\title{
Structural change in the Chicago region and the impact on emission inventories in a continuous-time modeling approach
}

\author{
Kieran Donaghy', Clifford R. Wymer ${ }^{2}$, Geoffrey J. D. Hewings ${ }^{3^{*}}$ and Soo Jung Ha ${ }^{4}$
}

*Correspondence:
hewings@illinois.edu
${ }^{3}$ Regional Economics
Applications Laboratory,
University of Illinois, 607 S.
Mathews, \#318, Urbana, IL
$61801-3671$, USA
Full list of author information
is available at the end of the
article

${ }^{*}$ Correspondence:

hewings@illinois.edu

Applications Laboratory,

University of Illinois, $607 \mathrm{~S}$

Mathews, \#318, Urbana, IL

Full list of author information article

\begin{abstract}
Motivated by both the need to model recent structural economic changes and the need to understand better the nature of environmental-economic interactions, this paper introduces a continuous-time regional econometric input-output model for the Chicago economy that can be used to analyze, at disaggregated sectoral and temporal levels, the economic and environmental implications of changes exogenous to the economy. The model's solution yields estimates of emission inventories, which may be used to analyze environmental implications of various economic changes and policy restrictions. This model is the first integrated economic-environmental model of which we are aware that has been formulated and estimated in continuous time for the regional economy of a metropolitan area. We believe that the model's formulation will enable it to enjoy greater compatibility with natural science-based models, which share such a formulation and flexibility in projecting future emissions corresponding to alternative future economic scenarios and in evaluating emissions policies relevant to such scenarios.
\end{abstract}

\section{Background}

Since at least the time of the industrial revolution, it has been observed that changes in economic activity can induce changes in the natural environment. Conversely, environmental changes can-and increasingly do-have economic consequences. For example, increased levels of by-production or trade will generally lead to increases in pollution, and high regional pollution levels will affect households' location choices. As the interactions between economic and environmental systems are becoming stronger and more apparent, anticipating and understanding environmental changes induced by economic activity is becoming increasingly challenging for both environmental scientists and economists and for policy makers who must ultimately choose strategies to balance risks and costs. Therefore, many researchers have turned to what are termed integrated assessment' frameworks, comprising both economic and environmental models, for the purpose of conducting simulations that might inform us about what environmental changes lie ahead if economic activity should follow particular paths (for example, see Igos et al. 2015). The economic models employed in such frameworks are based on

(c) The Author(s) 2017. This article is distributed under the terms of the Creative Commons Attribution 4.0 International License (http://creativecommons.org/licenses/by/4.0/), which permits unrestricted use, distribution, and reproduction in any medium, provided you give appropriate credit to the original author(s) and the source, provide a link to the Creative Commons license, and indicate if changes were made. 
prevailing economic theories and include input-output models, national and regional macroeconomic models, and computable general equilibrium models (CGE) (Igos et al. 2015). However, these economic models, which tend to be formulated in discrete time, can present difficulties both in linking with natural science-based models formulated in continuous time and in representing the ongoing development of environmental phenomena over time.

While the natural environment-especially the global climate-has been undergoing dramatically noticeable changes, even within the last decade alone (IPCC 2007), there have also been important developments in the structure of regional economies. For example, Munroe et al. (2007) have found that, in the USA, interstate trade has been increasing but is dominated by intra-industry trade for the Midwest states. Further, empirical analyses by Hewings et al. (1998) have revealed the workings of a 'hollowing out' process, which has resulted in a decrease in internal and an increase in external dependence on the economy of Chicago. Trade data suggest that the transportation intensity of production is greater than before and that non-polluting industrial sectors are likely to account for a larger share of economic activity than polluting sectors.

Motivated by both the need to model carefully these recent structural economic changes and the need to understand better the nature of environmental-economic interactions, we introduce in this paper a continuous-time regional econometric inputoutput model (REIM) for the Chicago economy (CREIM) that can be used to analyzeat disaggregated sectoral and temporal levels-the economic and environmental implications of changes exogenous to the economy. The model's solution yields estimates of emission inventories, which may be used to analyze environmental implications of various economic changes and policy restrictions. This model is the first integrated economic-environmental model of which we are aware that has been formulated and estimated in continuous time for the regional economy of a metropolitan area. ${ }^{1}$

The choice of Chicago for implementation of the continuous-time model was based on over two decades of experience with the annual REIM as well as the availability of detailed environmental data for the same region. We believe that the model's formulation will enable it to enjoy greater compatibility with natural science-based models, which share such a formulation, and flexibility in projecting future emissions corresponding to alternative future economic scenarios and in evaluating emissions policies relevant to such scenarios. In addition, the Chicago region typifies a formerly manufacturing-dependent region that has undergone a significant transformation to service dominance over the period from 1980 to 2015. The forecasted structural changes (see Israilevich et al. 1997, for details) suggest a more nuanced transformation of the remaining manufacturing sectors, such as those reported in Romero et al. (2009) that explored differences in spatial and functional fragmentation processes within the Chicago region.

In the next section, we discuss theoretical and empirical developments in integrated environmental-economic models, and in Sect. 3, we summarize the structure of the Chicago REIM (CREIM), which has provided the basis for our model, and the methodologies used to reformulate it in continuous time. Section 4 is composed of two parts: a

1 Tao et al. (2010) employ such a model to examine effects of structural change on emissions over the entire Midwest United States at a higher level of sectoral aggregation. 
presentation of the integrated econometric-emission modeling system with two types of emission intensity (EMI) and a presentation of their simulation results to 2050. Changes in simulated emission inventories presented in Sect. 4 are decomposed into two components: those due to technological changes and those due to the growth of production. This decomposition is performed in order to obtain an indication of which effect is likely to contribute more to future emission inventories. The implications of this decomposition are presented in Sect. 5. The paper concludes with a summary of the simulation results and suggestions for further research.

\section{Literature review}

Spatially referenced integrated environmental-economic models have shared some common frameworks. The economic component in integrated models usually consists of a regional or multiregional input-output model, a national or regional macroeconomic model or a general equilibrium model describing the relationships among the economic sectors of the region(s). The environmental component usually consists of models describing the generation and transport of pollutants and their subsequent interactions with the ecosystem of the region(s). In earlier studies attempting to assess quantitatively environmental impacts, two distinct models (Leontief 1970; Leontief and Ford 1972; Isard 1972) combined both the economic and environmental variables and their interactions in one operational form. Leontief (1970) and Leontief and Ford (1972) enlarged the traditional input-output model to account for the generation of pollutants by the economic system and the operation of anti-pollution activities. Isard (1972) suggested a synthesis of the economic with the ecologic system using an input-output format. His model described the interactions within each system separately and then between the economic and the ecologic systems. In the 1980s, input-output models were widely used as an economic component to link an environmental model (Forsund 1985; James 1985; Ketkar 1984; Lesuis et al. 1980; Pedersen 1996; Rhee and Miranowski 1984).

Since various input-output approaches such as a decomposition of the Leontief inverse matrix have been developed (Round 1985; Oosterhaven and van der Linden 1997; Sonis and Hewings 1992, 1996), more recent studies have used structural analyses in an input-output model in order to examine the relationship between economic patterns and the development of emissions (Munksgaard et al. 2000; Fritz et al. 2002; Lenzen et al. 2004). The role of private consumption affecting $\mathrm{CO}_{2}$ emissions in Denmark over 1966-1992 was analyzed by Munksgaard et al. (2000). Distinguishing between direct and indirect as well as domestic and imported $\mathrm{CO}_{2}$ emissions, Munksgaard et al. (2000) were one of the first to find that indirect emissions accounted for a major part of growth in total emissions from household consumption, although $\mathrm{CO}_{2}$ emissions from direct consumption still exceeded the emissions from indirect consumption. Other studies confirmed similar findings (e.g., Ivanova et al. 2016; Wiedmann et al. 2010; Wood and Dey 2009).

Fritz et al. (2002) adopted the field of influence approach of Sonis and Hewings (1992) to identify the changes in the direct coefficients table of an input-output model that created the largest impact on sectoral pollution multipliers. They pointed out that the service industries and some manufacturing sectors (for example, rubber and plastic) in the Chicago economy were increasing their output and employment and this growth is 
one of the indirect sources of air pollution by the non-polluting industries through their demands for inputs from polluting sectors. Hence, it is important to consider structural changes in formulating environmental regulations. In similar fashion, Lenzen et al. (2004) included a feedback-loop analysis with a detailed multiregional input-output model to calculate $\mathrm{CO}_{2}$ multipliers for trade between Denmark, Germany, Norway, Sweden and the rest of the world. They constructed an 1199 by 1199 matrix containing total, region-specific multipliers of intermediate demand, trade, energy consumption and $\mathrm{CO}_{2}$ emissions and then captured direct, indirect and induced effects of trade.

In addition to those studies using input-output models to integrate the relationship between economic and environmental sectors, many simulation models for environmental impact analyses have also integrated environmental components. Some earlier studies, such as Hazilla and Kopp (1990), Jorgenson and Wilcoxon (1990a, b) and Conrad and Schroder (1993), used CGE models to estimate the costs of environmental regulations. Especially after the Kyoto Protocol-which emerged from the United Nations Framework Convention on Climate Change (UNFCCC)—called for a reduction in the emissions of carbon dioxide and five other greenhouse gases (GHG), a number of approaches based on CGE modeling have been used to quantify the GHG emission as a result of economic activity (Babiker et al. 2001; Hertel and McDougall 2003; Springer 2002).

The MIT Emissions Prediction and Policy Analysis (EPPA) model has been used to analyze the processes that produce greenhouse-relevant emissions, and to assess the consequences of policy proposals intended to control these emissions with a CGE model of the world economy over a 100-year horizon (Babiker et al. 2001). Their emission scenarios are used as inputs into an atmospheric chemistry-climate model along with scenarios of natural emissions of GHGs from a natural emission model. Babiker et al. (2001) found that the inventory of climatically important substances highlighted the role of non-energy sources (e.g. agriculture, biomass burning) and developing countries as important current sources of many of these emissions.

Hertel and McDougall (2003) have developed a Global Trade Analysis Project (GTAP) model that is a static multiregional, multisectoral applied general equilibrium model. They have developed a land-use and greenhouse gas emission database to link model components together and assessed the costs of climate policies and their spillover effects via international trade and sectoral interaction. Springer (2002) has also assessed the allocational and distributional impacts of international climate policies, such as the Kyoto Protocol, on different regions of the world with the focus on the interaction of international trade in goods and international capital mobility. Springer's analysis used a dynamic, multiregional, multisectoral computable general equilibrium model. The empirical simulation analysis revealed that economic integration, as well as policies aimed at improving the diversification of the export structure of economics, might help to reduce the negative consequences connected with greenhouse gas abatement.

Specifications of the CGE models used in these studies are based on neoclassical theory with the central assumption being that all agents are acting with full information in perfectly competitive markets, so that all decisions are the result of optimization based on some assumption about the technology or the aggregate welfare function of the economy. There are other simulation models that follow macroeconomic theory and 
are based on assumptions that agents decide under conditions of bounded rationality in imperfect markets. The difference between these alternative models-e.g., COmprehensive Model of Policy ASSessment (COMPASS) (Uno 2002) and Global INterindustry FORecasting System (GINFORS) (Meyer et al. 2004)-and CGE models is that the former are macroeconometric input-output models. The core of both models is a multisectoral bilateral trade model and both systems characterize the interdependencies of economic and environmental development with respect to energy consumption. COMPASS and GINFORS are sectorally disaggregated and their behavioral parameters are estimated from time-series data by econometric methods. The estimated models are tested and equations are adapted until the models are able to reproduce history for a longer period. The models are then employed in simulations and forecasts of economic developments and their effects on markets and employment as well as global energy, resource and land consumption.

\section{Continuous-time modeling of CREIM}

\subsection{Chicago regional econometric input-output model (CREIM) ${ }^{2}$}

The Regional Economics Applications Laboratory (REAL) has constructed or overseen the construction of a number of impact and forecasting models for the Chicago metropolitan area, which encompasses Cook, Dupage, Kane, Lake, McHenry and Will counties. One such model, CREIM, is based on an initial formulation of Conway (1990, 1991), which was developed further by Israilevich et al. (1997). CREIM integrates econometric and input-output components, enabling impact analysis to be conducted as well as annual forecasts made for a 30-year horizon for up to 45 different NAICS-based ${ }^{3}$ industrial sectors (production, employment and income) and several major economic aggregates (such as gross regional product, wage rates, unemployment). CREIM is a computable regional general equilibrium model based on Marshallian equilibrium of outputs (see Takayama 1985). The model combines traditional input-output analysis with time-series analysis. The input-output component in this model enables a detailed analysis of purchases and sales between industries, while the time-series component allows for the analysis of intertemporal change in the transaction flows of goods and services. Together, these two components yield a detailed analysis of structural change over time at the sectoral level. By taking into account transaction flows between industries, CREIM is able to yield estimates of the spillover or indirect effects within the economy that direct analysis cannot capture because it examines each sector irrespective of its effect on other sectors.

CREIM uses the input-output component as a deterministic linear predictor of output:

$$
z_{i}^{t}=\sum_{j} a_{i j} x_{j}^{t}+\sum f_{i j} y_{j}^{t}+e_{i} n_{i}^{t} \quad \forall_{i}=1, \ldots, m
$$

where (disregarding the time superscript) $a_{i j}$ is the direct input requirement of sector $j$ from sector $i$, and $m$ is the number of sectors, $f_{i j}$ is a normalized regional purchase

\footnotetext{
2 This section draws on Israilevich et al. $(1996,1997)$ and Israilevich (2002).

${ }^{3}$ NAICS is the North American Industrial Classification System.
} 
coefficient of demand of sector $j$ from sector $i$ in the final demand matrix, $x_{j}$ is the total observed output of sector $j, Y=\left[\sum_{k=1}^{q} y_{k}\right]$ is the final demand vector consisting of $q$ components, namely, personal consumption, investment, government expenditure and net exports, $N=\left[n_{i}\right]$ is a vector of exogenous variables in regional economy such as GNP, national industrial production indices and other national data, $E=\left[e_{i}\right]$ is a vector of normalized regional gross export coefficients, $Z=\left[z_{i}\right]$ is the predicted output $\left(x_{i}\right.$ are observed output values), $t$ indicates the year at which output is predicted.

In order to formalize the difference between the traditional input-output approach and Eq. (1), Eq. (1) can be rewritten in matrix form:

$$
Z_{\text {REIM }}=A X+Y
$$

where $A$ is the input-output matrix and $Y$ is a vector of aggregated final demand that also includes the impact of the exogenous variables noted in (1); the time index is omitted to simplify and all variables change in time. Denote the difference between the observed and estimated output as $\Delta=Z_{\text {REIM }}-X$.

Then Eq. (2) can be expressed as:

$$
\begin{aligned}
& Z_{\mathrm{REIM}}=\Delta+X=A X+Y \\
& Z_{\mathrm{IM}}=(I-A)^{-1} Y \\
& \Delta+X-A X=\Delta+(I-A) X=Y
\end{aligned}
$$

Equation (4) then can be rewritten with Eq. (5) as:

$$
Z_{\mathrm{IM}}=(I-A)^{-1} Y=(I-A)^{-1} \Delta+X
$$

We can determine the difference between the input-output (IO) and CREIM estimation of outputs as:

$$
Z_{\mathrm{IM}}-Z_{\mathrm{CREIM}}=\left[(I-A)^{-1} \Delta+X\right]-(\Delta+X)=\left[(I-A)^{-1}-I\right] \Delta
$$

By using the power series decomposition of the Leontief inverse, we have:

$$
Z_{\mathrm{IM}}-Z_{\mathrm{CREIM}}=\left(A+A^{2}+A^{3}+\cdots+A^{\infty}\right) \Delta
$$

It is clear that the difference between the traditional input-output estimates and those generated by Eq. (1) from CREIM will be amplified by the structure of the $A$ matrix. Therefore, the differences between two estimates are related to the nature of the linkages between industries and can be measured by the indirect multiplier effects.

The dynamic equations of CREIM, in which adjustments in output, employment and income are made, are specified as autoregressive schemes to turn this model into an econometric forecasting model as described in the following equations.

$$
\log \left(\frac{x_{i}^{t}}{z_{i}^{t}}\right)=\alpha_{0}+\alpha_{z}\left(\frac{z_{i}^{t-1}}{x_{i}^{t-1}}\right)+\alpha_{g} g_{i}^{t}+\varepsilon_{i}^{t} \quad \forall i=1, \ldots, N ; \quad \forall t=1, \ldots, T
$$


where $z_{i}^{t-1}$ is a lagged input-output-generated predicted output and $g_{i}^{t}$ is the set of exogenous variables selected to explain the output variables.

Like Eq. (9) for output variables, the employment equation explains the relationship between an industry's total shipments and total employment. The equation is estimated with a dependent variable for the log of productivity. The equation is then normalized to isolate employment on the left-hand side.

$$
\log \left(\frac{n_{i}^{t}}{x_{i}^{t}}\right)=\alpha_{0}+\alpha_{z}\left(\frac{x_{i}^{t-1}}{n_{i}^{t-1}}\right)+\alpha_{g} g_{i}^{t}+\mu_{i}^{t} \quad \forall i=1, \ldots, N ; \quad \forall t=1, \ldots, T
$$

where $n_{i}^{t}$ is employment of sector $i$ at time $t, x_{i}^{t}$ is output of sector $i$ at time $t$ and $g_{i}^{t}$ is the set of exogenous variables selected to explain the employment variables.

The final equation in the industry block is the wage equation, also called the income equation. This equation describes the relationship between industrial employment and income. Again, the relationship is estimated with a dependent variable of the log of the ratio of income to employment that is equivalent to earnings per worker.

$$
\log \left(\frac{y_{i}^{t}}{n_{i}^{t}}\right)=\alpha_{0}+\alpha_{z}\left(\frac{n_{i}^{t-1}}{y_{i}^{t-1}}\right)+\alpha_{g} g_{i}^{t}+\psi_{i}^{t} \quad \forall i=1, \ldots, N ; \quad \forall t=1, \ldots, T
$$

where $y_{i}^{t}$ is income of sector $i$ at time $t, n_{i}^{t}$ is employment of sector $i$ at time $t$ and $g_{i}^{t}$ is the set of exogenous variables selected to explain the income variables.

Each industry grouping has a variable lag structure shown in Eqs. (9), (10) and (11), and when mixed with the econometric specifications of the final demand and demographic variables, the complete system of equations is then solved simultaneously and recursively (usually by a Gauss-Seidel method ${ }^{4}$ ) to determine the forecasted values of the endogenous variable. The procedure focuses on (9); the right-hand side can be defined as follows:

$$
\beta_{i}^{t}=\exp \left[\alpha_{o}+\alpha_{z}\left(\frac{z_{i}^{t-1}}{x_{i}^{t-1}}\right)+\alpha_{g} g_{i}^{t}\right]
$$

Hence, (9) can be rewritten as (dropping the time subscript):

$$
x_{i}=\beta_{i} z_{i}
$$

Converting $\beta_{i}$ to a diagonal matrix, $\hat{\beta}_{i}$, and utilizing (1), Eq. (9) can be presented as:

$$
X=\widehat{\beta} A X+\widehat{\beta} Y
$$

or finally as:

$$
X=[I-\widehat{\beta} A]^{-1} \widehat{\beta} Y
$$

\footnotetext{
${ }^{4}$ Standard routines using the Gauss-Seidel method are available in most mathematical packages such as Mathematica and MATLAB.
} 
Essentially $\hat{\beta}$ is a nonlinear, first difference operator that modifies the static Leontief inverse into a dynamic one. A set of exogenous variables influence the vector of exports. These help define the forecasted $Z$ 's that in turn are used in the system of Eqs. (2)-(8). Essentially, the process that equates $Z_{\mathrm{IM}}$ and $Z_{\mathrm{CREIM}}$ is accomplished by the adjustment of the $A$ matrix that, in turn, involves interaction with the whole set of economic-demographic interactions. Further details can be found in Israilevich et al. $(1996,1997)$.

\subsection{Continuous-time modeling ${ }^{5}$}

The use of REIMs, such as CREIM, to study the impacts of structural changes in a regional economy and their impacts on emissions inventories is a reasonable choice, since interindustry impacts need to be traced and the temporal staging of effects needs to be broken out. Most REIMs employed in applied research to date have been specified in discrete time for annually based time series. The dynamic equations of the models, in which adjustments in output, employment and income are made, tend to be specified as autoregressive schemes (see, for example, Eq. 11). For a judicious selection of regressors, whether endogenously or exogenously determined, much of the systematic variation in the difference between predicted and observed sectoral output can be accounted for, as can the variation in sectoral employment and income. Such models can be, and have been, used to convey a sense of what impacts are likely to have accumulated 1 year out, 2 years out, etc. (see Israilevich et al. 1997).

Where such models come up short is in indicating what the transition paths of sectoral adjustments would be at points in between the yearly intervals and, as noted above, what the short-term impacts of subinterval events would be. ${ }^{6}$ Of course, one can interpolate between solution points, but difference equations, by their nature, characterize what transpires at the end of one period and the beginning of the next, not what happens at points in between. So there is nothing in the specification of the model to suggest what shape an adjustment lag may assume. REIMs may also mislead us about the effects of unexpected events. Because the dynamic equations of REIMs are essentially autoregressive data mining constructs, they may not represent causal relations. Hence, some simulations can produce counterintuitive results, where feedback relationships or constraints dictated by theory are not present. As discussed above, these properties leave one illequipped to link a REIM with other models, which depict the continuous unfolding of events over periods of time that are shorter than the observation or solution interval of the REIM.

One response to this situation is to re-specify the model in continuous time. Theoretical developments and software availability have permitted approximate and exact econometric estimation of linear continuous-time models (of both the structural-equation and frequency-domain varieties) from discrete-time observations since the early

\footnotetext{
5 The first part of this section closely follows Donaghy et al. (2007).

${ }^{6}$ A good example of this problem is the modeling of the impact of floods; work by Hewings and Mahidhara (1996) revealed that over the course of a year, the negative impacts of the flood were often more than compensated by the growth impacts generated by federal and state disaster assistance programs. In this case, having a model that could chart the process on a weekly or monthly basis would have been incredibly valuable. In the case of the Katrina impact on New Orleans, the need for continuous time modeling in the recovery process was even more compelling, especially given the out-migration of one-third of the region's population and the significant loss of capital stock. See Donaghy et al. (2007) for a demonstration of how a continuous-time REIM can be used to model the occurrence and recovery from extreme events.
} 
1970s (Wymer 1972; Bergstrom 1976; Harvey 1989), whereas approximate estimation of nonlinear differential equation systems has been possible since the mid-1970s and exact estimation since the early 1990s (Wymer 1993, 1997). Recently, continuous-time models have been extended to economic growth and convergence studies (Arbia and Paelinck 2003) and various fields of spatial dynamic modeling (Donaghy 2001; Donaghy and Plotnikova 2004; Donaghy et al. 2007; Piras et al. 2007; Oud and Folmer 2008).

The continuous-time approach to specification, estimation and analysis has several features to recommend it for modeling structural changes in regional economies and their relationship with environmental systems. Continuous-time models provide a better characterization of ongoing aggregate economic activity than discrete-time models, and permit better handling of mixed samples (i.e., samples including data on stocks, flows, derivatives, point observations and period averages). The estimates of continuoustime system parameters tend to be more efficient than their discrete-time system counterparts (Phillips 1991), and estimates of adjustment parameters, hence adjustment lags, are independent of the observation interval. Perhaps most importantly, once the parameters of a continuous-time system have been estimated, the model can (in theory) be solved for any time interval (on all these well-established points, see Gandolfo 1981). There are at least two other potential advantages to putting REIMs into a continuoustime formulation: (1) it provides an opportunity to introduce explicit functional forms suggested by theoretical explanations of events, or adjustment patterns, and to test explanations (i.e., to eliminate some of the 'black box' character of REIMs) and (2) it becomes possible to obtain point estimates of interindustry coefficients at a particular time period, even between empirical observations. ${ }^{7}$

There are some trade-offs in moving from a discrete-time to a continuous-time specification. One is that we forego some flexibility in capturing unsynchronized lags and leads for the effects of different regressors. Since Allen (1965), however, it has been well appreciated that continuous-time models with second-order (and higher-order) exponential lags can capture the shape of a broad spectrum of lag structures likely to be encountered among macroeconomic phenomena and, further, these lags can be implemented in a straightforward manner. For example, assume that at a given point in time, $t$, the underlying theoretical relationship between some endogenous variable, $Y(t)$, and several predetermined variables, $X_{1}(t), X_{2}(t)$ and $X_{3}(t)$ is:

$$
Y(t)=\alpha X_{1}(t) X_{2}(t) X_{3}(t),
$$

in which all variables are in levels and a possible additive stochastic error term is ignored for the sake of exposition. A first-order exponential lag relationship can be written as:

$$
D \log Y(t)=\gamma \log \left(\alpha X_{1}(t)^{\beta_{1}} X_{2}(t)^{\beta_{2}} X_{3}(t)^{\beta_{3}} / Y(t)\right)
$$

in which $1 / \gamma$ is the mean adjustment lag and $D=d / d t$ is the time differential operator. A second-order lag can be written as:

$$
D y(t)=\gamma^{\prime} \gamma \log \left(\alpha X_{1}(t)^{\beta_{1}} X_{2}(t)^{\beta_{2}} X_{3}(t)^{\beta_{3}} / Y(t)\right)-\gamma^{\prime} y(t)
$$

\footnotetext{
7 See Appendix B of Donaghy et al. (2007) for the derivation of formulas for updating estimates of interregional interindustry sales coefficients in a REIM at a given data point.
} 
in which $y(t)=D \log Y(t)$. This equation can be used as a prototype for dynamic adjustment equations in a continuous-time specification of CREIM.

Information on the structure of the discrete-time CREIM was used to re-specify the model in continuous time (i.e., in terms of differential equations). In the interest of developing a model with a stable solution in simulations extending well beyond the sample period, we imposed a negative feedback disequilibrium adjustment relationship in each of the differential equations determining the value of an endogenous variable that was not an accounting identity. The continuous-time model was estimated with annual data for the period from 1969 to 2000.

Because of the size of the overall model and the paucity of time-series observations, the model was estimated piecemeal by blocks of equations corresponding to actual output, employment, income, population and final demand using a nonlinear quasi-fullinformation maximum-likelihood (FIML) estimator in the program ESCONA of Wymer's (2004) WYSEA package. (See Fig. 1; Wymer (1993) and Donaghy et al. (2007) provide details of the estimation algorithm. $)^{8}$ In estimating each block, some variables that were, in theory, endogenously determined in the complete model (and were treated endogenously in another block) were of necessity treated as exogenous. The separate estimated blocks of equations were then integrated into the omnibus modeling framework.

Since out-of-sample values of the exogenous variables are needed to conduct simulations beyond the period for which observations are available, a zero-order forcing function of time was also estimated for each of the exogenous variables. Assuming that the values of the coefficients of the forcing functions should be determined independently of the model's parameters, the forcing functions to be used in generating future values of exogenous variables were estimated separately from the other equation blocks in the model.

The consistency and overall coherence of the continuous-time model, constructed and estimated as indicated in Fig. 1, were checked by obtaining dynamic solutions of the integrated estimated model over the sample period and comparing the model solution values with the observed data, as discussed below. The appropriateness of using the model for out-of-sample simulations was checked by obtaining a long-run out-of-sample dynamic solution to the model based on initial values of the endogenous variables and the forcing functions of time representing the exogenous variables. As noted above, advantages of employing a continuous-time REIM for conducting out-of-sample simulations are its long-term stability and its ability to be solved at time intervals (perhaps, reflecting seasonal effects) that are different from the observation intervals of the data used to calibrate it.

For illustrative purposes, Figs. 2, 3 and 4 present the in-sample estimated output variables for an aggregation of the 45 sectors to 6 sectors (resources, construction, nondurable manufacturing, durable manufacturing, TCU (transportations, communications

\footnotetext{
${ }^{8}$ We should point out that in large discrete-time regional econometric input-output models, such as CREIM, the major blocks of relationships are also estimated separately and then integrated into a complete system. The consistency of such an integrated model may be checked, as shown in Israilevich et al. (1997) by deriving an appropriate measure from the $A^{t}$ matrices extracted for each year. Out-of-sample forecasts can be made with the discrete-time model by using exogenous national forecasts to drive the system beyond calibration years.
} 

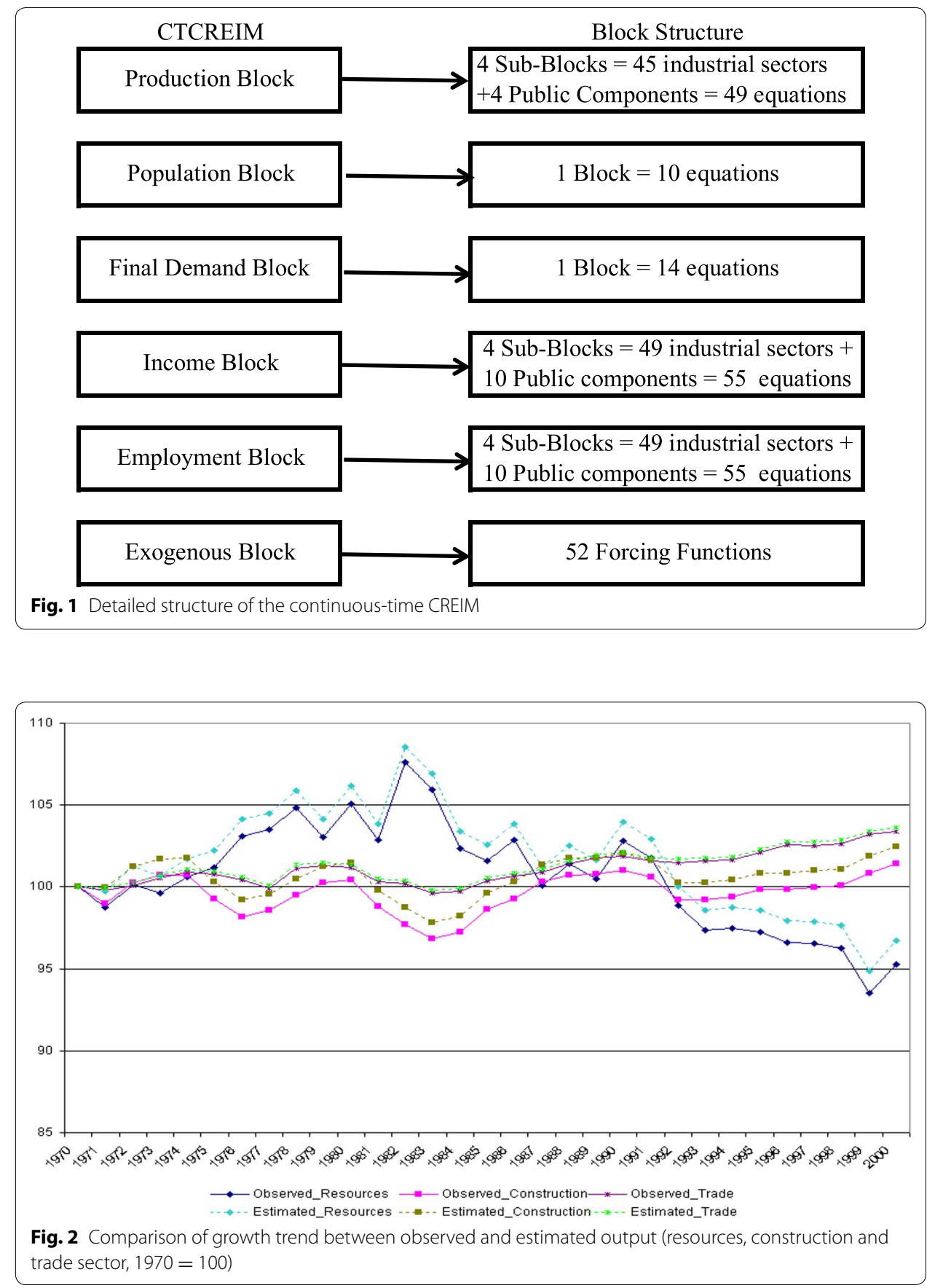

and utilities), trade, FIRE (finance, insurance and real estate), services and government). The growth trends of the estimation results relative to base year (1970) are provided in comparison with the annual observed trends derived from CREIM. Output levels of all sectors fluctuated strongly in the 1980s (see Hewings et al. 1998 for explanation), and the estimated model captures these dynamics very well.

In Fig. 2, one can see that the aggregate output of the resource sectors increased by $8 \%$ from 1969 until the early 1980s, after which it decreased steadily until, in 2000, it was 

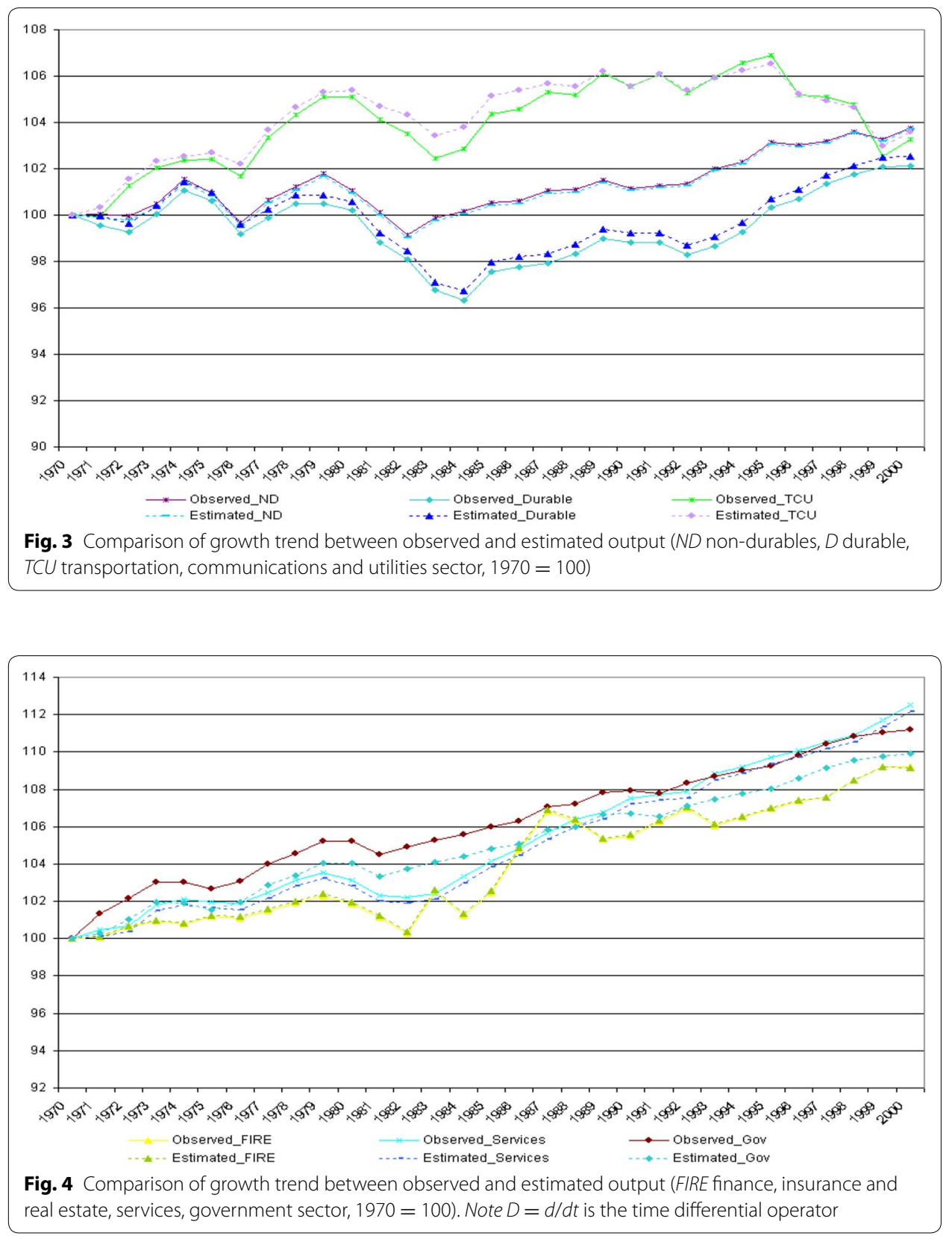

$5 \%$ lower than in the base year. The trend of construction and trade output was upwards except for a drop in the early 1980s. Estimated and observed output levels of durable and non-durable manufacturing and TCU are portrayed in Fig. 3. Output of durable manufacturing decreased in 1980s and was less than that of non-durable manufacturing from 1970 to 2000 . But, both sectors recovered and by 2000 showed $2-4 \%$ increases relative to the base year. By contrast, the output of TCU increased by 7\% as of 1995 but then decreased through the rest of the sample period. Figure 4 indicates that, in comparison with other sectors, the output levels of FIRE, services and government sectors achieved period increases of 9,10 and $12 \%$, respectively. 
Figures 2, 3 and 4 confirm that the estimated continuous-time CREIM fits the historical database well. Table 1 presents the means and standard deviations of the output variables and the normalized root-mean-square error (RMSE divided by the mean) of the in-sample dynamic forecasts for estimated output produced by the model. The

Table 1 In-sample forecasting errors of the estimated output

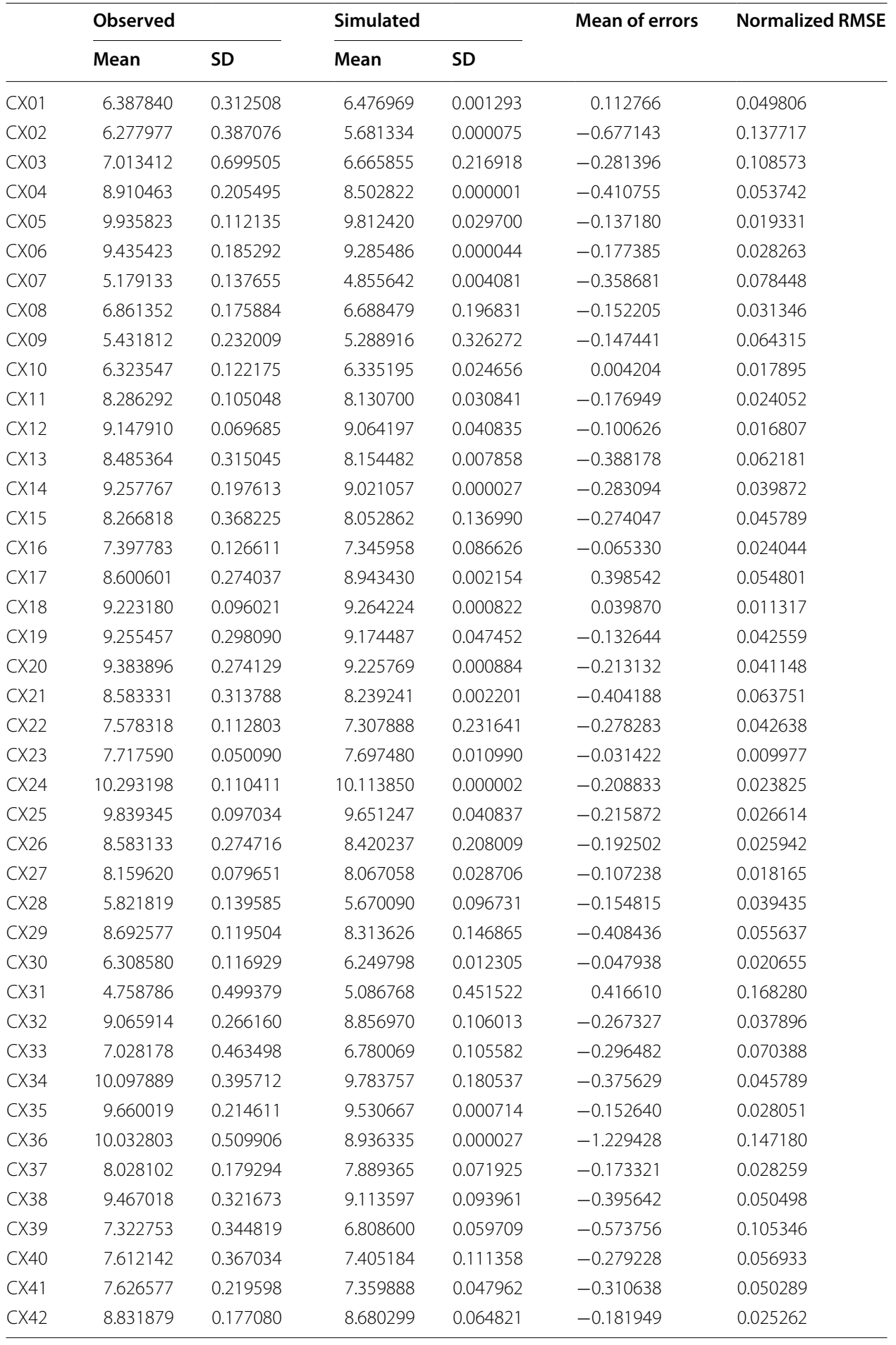


Table 1 continued

\begin{tabular}{|c|c|c|c|c|c|c|}
\hline & Observed & & Simulated & & Mean of errors & Normalized RMSE \\
\hline & Mean & SD & Mean & SD & & \\
\hline$\overline{C X 43}$ & 8.509383 & 0.420159 & 8.504962 & 0.322716 & -0.064855 & 0.019675 \\
\hline CX44 & 7.621232 & 0.120332 & 7.260127 & 0.206786 & -0.389088 & 0.065912 \\
\hline CX45 & 8.081027 & 0.118887 & 8.092222 & 0.071850 & -0.006324 & 0.010464 \\
\hline CXFG & 7.164935 & 0.193000 & 7.04079 & 0.11692 & -0.153257 & 0.024560 \\
\hline CXSL & 7.752615 & 0.196951 & 7.65825 & 0.15712 & -0.123279 & 0.017269 \\
\hline
\end{tabular}

The preface CX refers to Chicago output; the following number refers to the sectors whose definition is provided in Table 2 . CXFG and CXSL refer to federal government and state and local government

imposition of the feedback structure (discussed above) may have resulted in RMSEs that were, in some cases, higher than could have been obtained with more widely used vector autoregressive specifications. However, Table 1 and Figs. 2 through 4 suggest the model solution with negative feedback adjustments imposed is consistent with the historical data that have been used to estimate REIMs for Chicago. To complete a qualitative analysis of the estimated model, formal analyses of local and global stability properties and sensitivity analyses would need to be conducted.

To examine the model's suitability for use in dynamic simulations out of sample, we solved it forward for 50 years without any policy intervention. While the model can be solved for any frequency desired, we highlight the solution at annual intervals. The results of this out-of-sample simulation suggest that the model, when linked with an appropriate emissions inventory component, will support investigations of the relationships between structural changes in a regional economy and changes in emissions inventories.

The solution obtained for this baseline simulation, and portrayed in Fig. 5, suggests that, with the exception of durable manufacturing and TCU, output levels of the

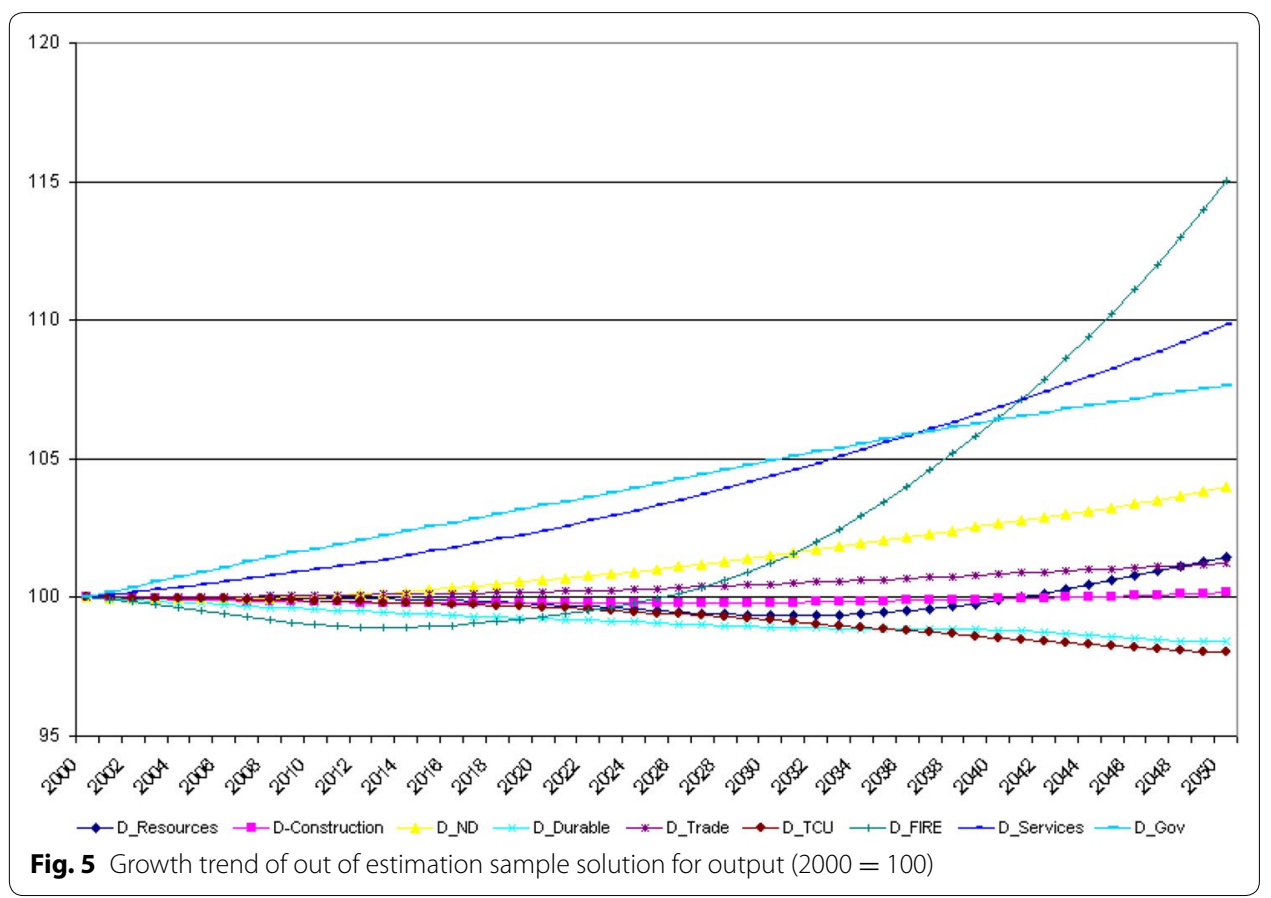


aggregated industrial sectors of the Chicago regional economy will increase steadily. The output of the resource sector is predicted to grow by $1.4 \%$ relative to its output level in 2000. The smallest increase, $0.2 \%$, is shown in the construction sector. While in this solution the output of non-durable manufacturing and trade rises 4 and 1.2\%, respectively, durable manufacturing and TCU decrease by 1.6 and $2 \%$ compared to their base values in 2000. Higher growth changes in FIRE, services and government sectors are forecasted to increase by $15,9.8$ and $7.7 \%$, respectively.

In the next section, we discuss the integration of the continuous-time CREIM with a block of equations characterizing emissions of air pollutants for the Chicago region. The integrated modeling system will then be employed to examine potential effects on emissions of structural changes in the economy.

\section{The integrated econometric-emission modeling system ${ }^{9}$}

The strategy for predicting future emissions is to develop an integrated modeling system whose solution yields annual emission inventories based on detailed output from a continuous-time CREIM (hereafter, CT-CREIM). The detailed output of CT-CREIM, for 45 sectors, makes it possible to construct emission inventories that match the 1999 National Emissions Inventory (NEI99). The basic emission identification of NEI99 is the source characterization code (SCC) in which each source category is divided into industry groups and further classified within the source category. The integrated econometric-emission modeling system uses the output of the CT-CREIM to identify SCCs in NEI99 for the point and area emission sources and calculates the associated emission factors and the activity level. As a first step in this study, we introduce emission intensity coefficients, which are based on historically observed emissions and levels of emission activities. These coefficients will be used to augment the CT-CREIM model to forecast emissions under different scenarios (see Fig. 6).

\subsection{Emission intensity (EMI)}

The development of the emission intensity coefficients discussed in this section is derived from Tao et al. (2007). In the present study, we consider the seven so-called criteria pollutants on which the US EPA maintains emissions inventories-carbon monoxide $(\mathrm{CO})$, nitrogen oxide $\left(\mathrm{NO}_{x}\right)$, sulfur dioxide $\left(\mathrm{SO}_{2}\right)$, particular organic compound $\left(\mathrm{PM}_{10}\right.$ and $\mathrm{PM}_{2.5}$ with diameter less than 10 and $\left.2.5 \mu \mathrm{m}\right)$, volatile organic compound (VOC) and ammonia $\left(\mathrm{NH}_{3}\right)$. To analyze the production of emissions stocks, we will employ two different types of emission intensity coefficients: those that are assumed to be fixed through time and those that are time varying.

We develop future emission inventories in a manner similar to traditional approaches, in which emissions are a function of emission intensity (EMI) and levels of emission activities:

$$
\text { Emission }=\text { EMI } \times \text { activity, }
$$

where EMI is defined by the emissions per unit of activity (ton/million \$).

\footnotetext{
${ }^{9}$ Further details may be found in Tao et al. (2007).
} 


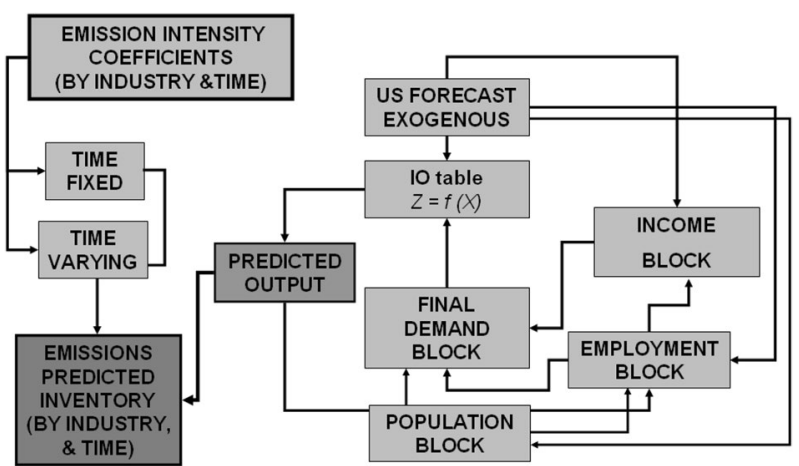

Fig. 6 Overview of the integrated econometric-emission modeling system

Emission intensities are usually calculated from data given in the 1999 National Emissions Inventory (NEI99). Calculating the coefficients from these data has the two advantages that the emission inventories will be available in a generally accepted format and the growth factors can be compared easily with other work in this area. To calculate the coefficients, the emissions from NEI99 inventories based on Source Classification Codes (SCCs) are first mapped into Standard Industrial Classification (SIC) codes. All point source SCCs and approximately $16 \%$ of area source SCCs can be associated with SIC codes. The remaining $80 \%$ area SCCs are assigned to a particular SIC following the EGAS mapping (Economic Growth Analysis System) ${ }^{10}$ and an inferential analysis of SCC and SIC coding. Note that the remaining $4 \%$ of the area sources related to household activities and on-road mobile sources are excluded in this research. The point and area sources covered here are only $48 \%$ of total emission pollutants in the Chicago region. The resulting SCC-SIC mapping is then converted to NAICS on which the economic sectors of the CT-CREIM are based (see Table 2). In order to support particular thought experiments, to be discussed below, the fixed emission intensities, as calculated from NEI99, are assumed to remain constant into future. The implication of this assumption is that all emission changes result only from activity changes.

To accommodate changes in EMIs related to shifts of energy usage, technological change and increasing demand of environmental protection, Tao et al. (2007) also developed time-varying sectoral emissions intensity coefficients from 1970 to 2002. Timevarying EMIs were calculated using the NEI Air Pollutant Emission Trend data. ${ }^{11}$ Subsequently, the average annual percentage change rate (\%) in EMI from each activity was calculated using Eq. (17).

$$
\mathrm{EMI}_{t}=\mathrm{EMI}_{0} \times\left(1+\frac{\text { rate }}{100}\right)^{n}
$$

where $\mathrm{EMI}_{t}$ is $\mathrm{EMI}$ for some future year $t ; \mathrm{EMI}_{0}$ is base year (1999) EMI; rate is the average annual EMI change (\%); and $n$ is the number of years from 1999. This average annual EMI change reflects, collectively, the influence of historical technological, economic

\footnotetext{
${ }^{10} \mathrm{http} / / /$ www.epa.gov/ttn/chief/emch/projection/index.html.

${ }^{11} \mathrm{http} / / / \mathrm{www}$.epa.gov/ttn/chief/trends.
} 
Table 21999 fixed emissions intensities (EMI) in Chicago region

\begin{tabular}{|c|c|c|c|c|c|c|c|c|}
\hline & Industry sector & $\mathrm{CO}$ & $\mathrm{NH}_{3}$ & $\mathrm{NO}_{x}$ & $\mathrm{PM}_{10}$ & $\mathrm{PM}_{2.5}$ & $\mathrm{SO}_{2}$ & VOC \\
\hline 1 & Livestock and other ag. products & 0.099 & 8.064 & 0.067 & 29.002 & 5.800 & 0.034 & 0.049 \\
\hline 2 & Agriculture, forestry and fisheries & 319.62 & 0.015 & 4.981 & 0.984 & 0.904 & 0.464 & 24.555 \\
\hline 3 & Mining & 1.184 & 0.001 & 0.763 & 6.934 & 1.716 & 0.102 & 0.164 \\
\hline 4 & Utilities & 0.866 & 1.099 & 8.196 & 0.399 & 0.322 & 11.737 & 0.221 \\
\hline 5 & Construction & 1.178 & 0.001 & 0.734 & 1.422 & 0.342 & 0.097 & 0.608 \\
\hline 6 & Food and kindred products & 0.568 & 0.001 & 0.463 & 0.169 & 0.109 & 0.253 & 0.177 \\
\hline 7 & Tobacco product manufacturing & 0.517 & 0.001 & 0.129 & 0.024 & 0.019 & 0.032 & 0.410 \\
\hline 8 & Apparel and textile products & 0.525 & 0.001 & 0.129 & 0.034 & 0.027 & 0.064 & 0.254 \\
\hline 9 & Leather and leather products & 0.533 & 0.001 & 0.155 & 0.032 & 0.027 & 0.033 & 0.480 \\
\hline 10 & Lumber and wood products & 0.559 & 0.002 & 0.233 & 0.212 & 0.133 & 0.033 & 0.781 \\
\hline 11 & Paper and allied products & 0.562 & 0.053 & 0.199 & 0.100 & 0.077 & 0.034 & 1.125 \\
\hline 12 & Printing and publishing & 0.518 & 0.001 & 0.123 & 0.026 & 0.024 & 0.037 & 0.481 \\
\hline 13 & Petroleum and coal products & 0.794 & 0.086 & 1.460 & 0.245 & 0.204 & 9.792 & 3.864 \\
\hline 14 & Chemicals and allied products & 1.437 & 0.002 & 0.332 & 0.152 & 0.122 & 0.159 & 0.774 \\
\hline 15 & Rubber and misc. plastics products & 0.553 & 0.002 & 0.148 & 0.059 & 0.045 & 0.034 & 0.771 \\
\hline 16 & Stone, clay and glass products & 0.936 & 0.001 & 1.374 & 0.582 & 0.286 & 3.573 & 0.130 \\
\hline 17 & Primary metals industries & 10.074 & 0.002 & 1.578 & 1.417 & 1.264 & 1.326 & 1.354 \\
\hline 18 & Fabricated metal products & 0.589 & 0.002 & 0.202 & 0.067 & 0.057 & 0.048 & 1.792 \\
\hline 19 & Industrial machinery and equipment & 0.529 & 0.001 & 0.148 & 0.031 & 0.028 & 0.036 & 0.285 \\
\hline 20 & $\begin{array}{l}\text { Computer and other electric product compo- } \\
\text { nent manufacturing }\end{array}$ & 0.520 & 0.013 & 0.129 & 0.043 & 0.038 & 0.043 & 0.649 \\
\hline 21 & Transportation equipment manufacturing & 0.534 & 0.001 & 0.202 & 0.032 & 0.027 & 0.036 & 0.350 \\
\hline 22 & Furniture and related product manufacturing & 0.532 & 0.001 & 0.177 & 0.092 & 0.065 & 0.059 & 2.850 \\
\hline 23 & Miscellaneous manufacturing & 0.550 & 0.001 & 0.137 & 0.032 & 0.029 & 0.055 & 2.103 \\
\hline 24 & Wholesale trade & 0.662 & 0.000 & 0.042 & 0.019 & 0.016 & 0.044 & 0.065 \\
\hline 25 & Retail trade & 0.662 & 0.000 & 0.036 & 0.013 & 0.012 & 0.038 & 0.130 \\
\hline 26 & Air transportation & 1.479 & 0.000 & 0.929 & 0.029 & 0.021 & 0.087 & 0.293 \\
\hline 27 & $\begin{array}{l}\text { Railroad transportation and transportation } \\
\text { services }\end{array}$ & 0.466 & 0.000 & 3.416 & 0.094 & 0.086 & 0.208 & 0.152 \\
\hline 28 & Water transportation & 3.957 & 0.000 & 29.315 & 1.394 & 1.252 & 4.542 & 2.706 \\
\hline 29 & Truck transportation and warehousing & 0.061 & 0.000 & 0.025 & 7.197 & 1.427 & 0.005 & 0.211 \\
\hline 30 & Transit and ground passenger transportation & 0.055 & 0.000 & 0.002 & 7.195 & 1.425 & 0.000 & 0.028 \\
\hline 31 & Pipeline transportation & 0.095 & 0.000 & 0.105 & 0.006 & 0.006 & 0.000 & 9.747 \\
\hline 32 & Information & 0.055 & 0.000 & 0.003 & 0.006 & 0.006 & 0.000 & 0.004 \\
\hline 33 & Motion picture and sound recording industries & 0.660 & 0.000 & 0.035 & 0.012 & 0.011 & 0.037 & 0.031 \\
\hline 34 & Finance and insurance & 0.661 & 0.000 & 0.036 & 0.012 & 0.011 & 0.037 & 0.031 \\
\hline 35 & Real estate & 0.670 & 0.000 & 0.047 & 0.014 & 0.012 & 0.041 & 0.032 \\
\hline 36 & $\begin{array}{l}\text { Professional and management services and } \\
\text { other support services }\end{array}$ & 0.665 & 0.000 & 0.049 & 0.014 & 0.013 & 0.043 & 0.034 \\
\hline 37 & Educational services & 0.787 & 0.001 & 0.357 & 0.037 & 0.031 & 0.200 & 0.042 \\
\hline 38 & Health care & 0.692 & 0.000 & 0.102 & 0.016 & 0.015 & 0.052 & 0.036 \\
\hline 39 & Social services & 0.660 & 0.000 & 0.035 & 0.012 & 0.011 & 0.039 & 0.031 \\
\hline 40 & Arts, entertainment and recreation & 11.892 & 0.001 & 0.296 & 0.165 & 0.152 & 0.060 & 3.498 \\
\hline 41 & Accommodation services & 0.664 & 0.000 & 0.043 & 0.013 & 0.012 & 0.038 & 0.031 \\
\hline 42 & Food services & 0.660 & 0.000 & 0.035 & 0.012 & 0.011 & 0.037 & 0.031 \\
\hline 43 & Repair and maintenance & 0.661 & 0.000 & 0.037 & 0.016 & 0.014 & 0.037 & 0.849 \\
\hline 44 & Personal and laundry services & 0.685 & 0.002 & 0.077 & 0.018 & 0.016 & 0.057 & 2.221 \\
\hline 45 & $\begin{array}{l}\text { Memberships organizations and private house- } \\
\text { holds }\end{array}$ & 0.668 & 0.000 & 0.046 & 0.013 & 0.012 & 0.047 & 0.033 \\
\hline GE & Government enterprises & 0.223 & 0.000 & 0.228 & 0.099 & 0.070 & 0.032 & 0.284 \\
\hline
\end{tabular}


and policy changes. For this study, it is assumed that there was no EMI change in the future-i.e., rate $=0$-if the historical average annual EMI change was positive. The EMI change rates listed in Table 3 were then assigned to each CREIM sector.

\subsection{Simulation of the model out of estimation sample}

Dynamic simulations of the integrated econometric-emission model were conducted by solving the model forward over the period from 2001 to 2050. Initial values of the endogenous variables were taken from year 2000 data, and the time paths of the exogenous variables were extrapolated from the forcing functions of time, whose estimation was discussed earlier. The dynamic simulations were conducted using Wymer's program APREDIC in his WYSEA package, which solves the set of nonlinear differential equations comprising the model with a variable-step, variable-order Adams method (see Shampine and Gordon 1975).

To demonstrate the process of emission inventory development, we conducted a baseline simulation in which we projected emissions assuming no technological changes in the future. In this case, the current fixed emissions intensity coefficients based on the NEI99 inventory were used to calibrate a block of emissions equations in the econometric model. Since, in this simulation, any future emission changes are driven solely by future industrial activity levels, it is also necessary to conduct a second simulation in which time-varying EMIs are used to project future emissions that reflect the effect of technological advances in addition to changes in industrial activity levels.

In the case of fixed EMI (illustrated in Fig. 7), emissions of CO, $\mathrm{NO}_{x}, \mathrm{PM}_{2.5}, \mathrm{SO}_{2}$ and VOC increase by 78, 30, 1, 4 and 40\%, respectively, by 2050 . Only the emissions of $\mathrm{PM}_{10}$ are reduced by $10 \%$. Compared to projected emissions under the fixed EMI, future EMI changes modeled by Eq. (20) using the historic change rates of EMI are shown in Table 3. Under the time-varying EMI, the relative contribution to emissions from each industry changes at a different pace due to the different technology growth rates. This outcome implies that emissions change as a result of the combined effects of economic structural change as well as changes in technology- and environment-related policy represented by time-varying EMI.

Projected emissions under the assumption of time-varying EMIs are significantly reduced, as shown in Fig. 8. Emissions of $\mathrm{CO}, \mathrm{NH}_{3}, \mathrm{NO}_{x}, \mathrm{PM}_{10}, \mathrm{PM}_{2.5}, \mathrm{SO}_{2}$ and VOC are reduced by $57,92,60,55,47,35$ and $27 \%$, respectively, in comparison with the fixed EMI case in 2050. All pollutants except CO experience a steady decline from 1999 to 2050 under an overall decreasing trend in time-varying EMI. CO emissions are reduced by $74 \%$ in 2030 but grow again by $2 \%$ in 2050 compared with their 1999 level. This result

Table 3 Average annual EMI change rate (\%) in the Chicago region

\begin{tabular}{lrrrrrrr}
\hline & \multicolumn{1}{c}{$\mathbf{C O}$} & \multicolumn{1}{c}{$\mathbf{N H}_{\mathbf{3}}$} & $\mathbf{N O}_{\boldsymbol{x}}$ & $\mathbf{P M}_{\mathbf{1 0}}$ & $\mathbf{P M}_{\mathbf{2 . 5}}$ & $\mathbf{S O}_{\mathbf{2}}$ & \multicolumn{1}{c}{$\mathbf{V O C}$} \\
\hline Resources & 0.000 & 0.000 & 0.000 & 0.000 & 0.000 & 0.000 & 0.000 \\
Construction & 0.000 & -5.644 & 0.000 & -1.680 & 0.000 & 0.000 & -1.173 \\
Non-durable manufacturing & -4.326 & -14.669 & -2.065 & -4.713 & -2.230 & -3.747 & -3.276 \\
Durable manufacturing & -2.490 & -6.026 & -0.554 & -5.703 & -4.882 & -3.918 & -2.613 \\
Trade and services & -1.070 & 0.000 & -2.369 & -1.655 & -2.008 & -4.292 & -3.042 \\
\hline
\end{tabular}



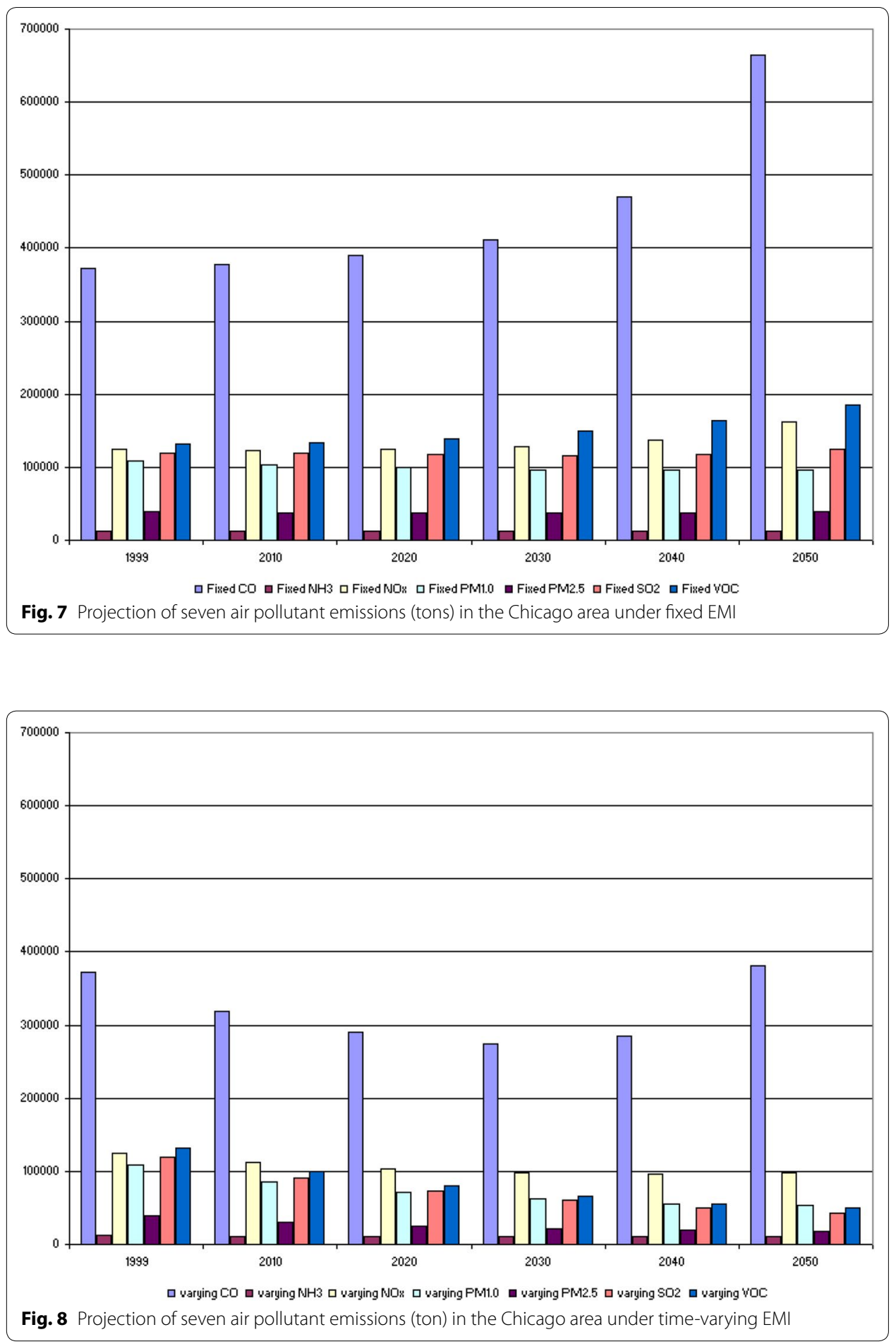

implies that the future economic structure of Chicago area would contribute to an increase in $\mathrm{CO}$ emissions by 2050 in spite of the declining trend of time-varying EMI. These results will be discussed in more detail in the analysis of the sectoral percentage distribution of projected emissions. 
Figures 9, 10 and 11 present profiles of pollutant emissions for the 9 different aggregate industry groups under the two different assumptions about emissions intensity. In 1999, the base year (see Fig. 9), resources, durable manufacturing and TCU accounted for the largest shares of overall pollution emissions. For example, resources contributed $25 \%$ of all $\mathrm{CO}$ emissions, $51 \%$ of $\mathrm{NH}_{3}$ (51\%), 25\% of PM10, while TCU generated $43 \%$

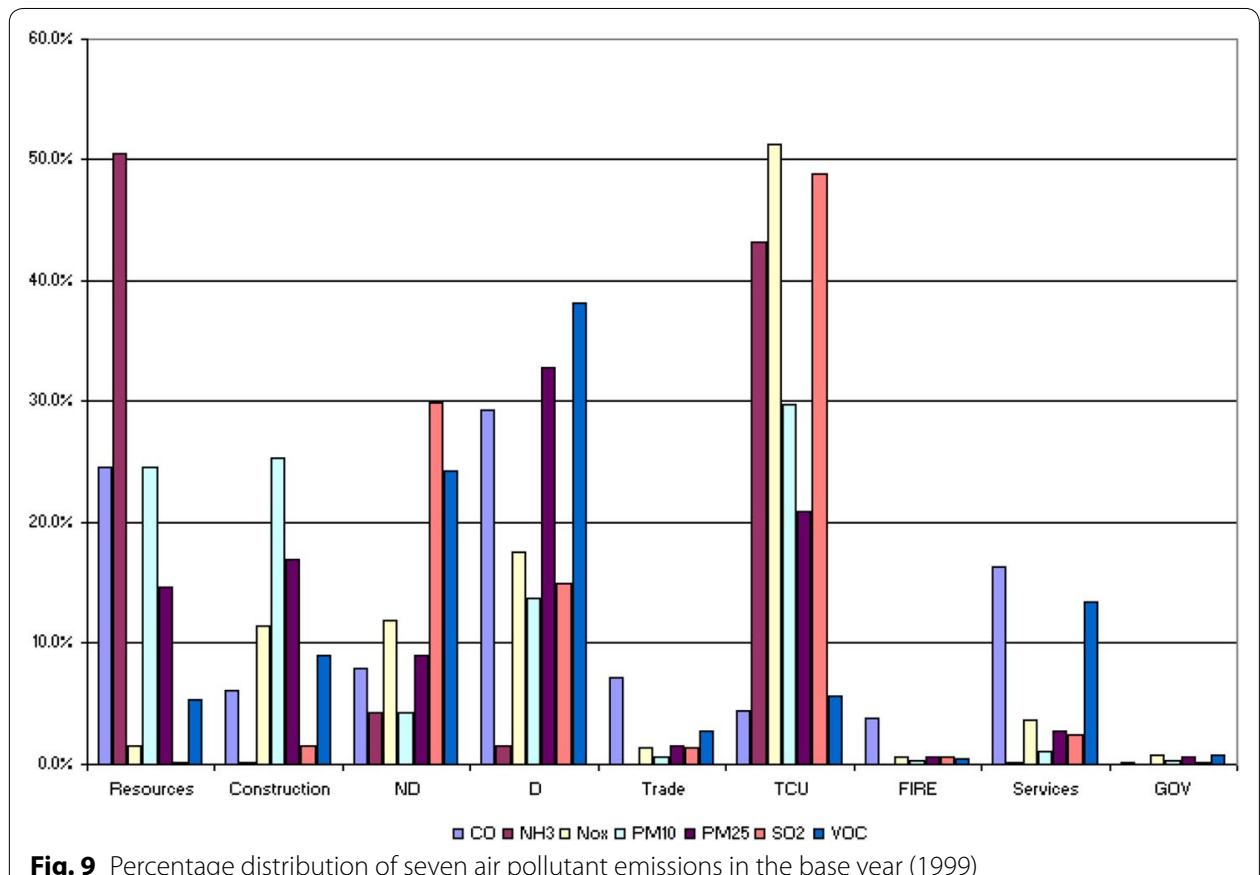

Fig. 9 Percentage distribution of seven air pollutant emissions in the base year (1999)

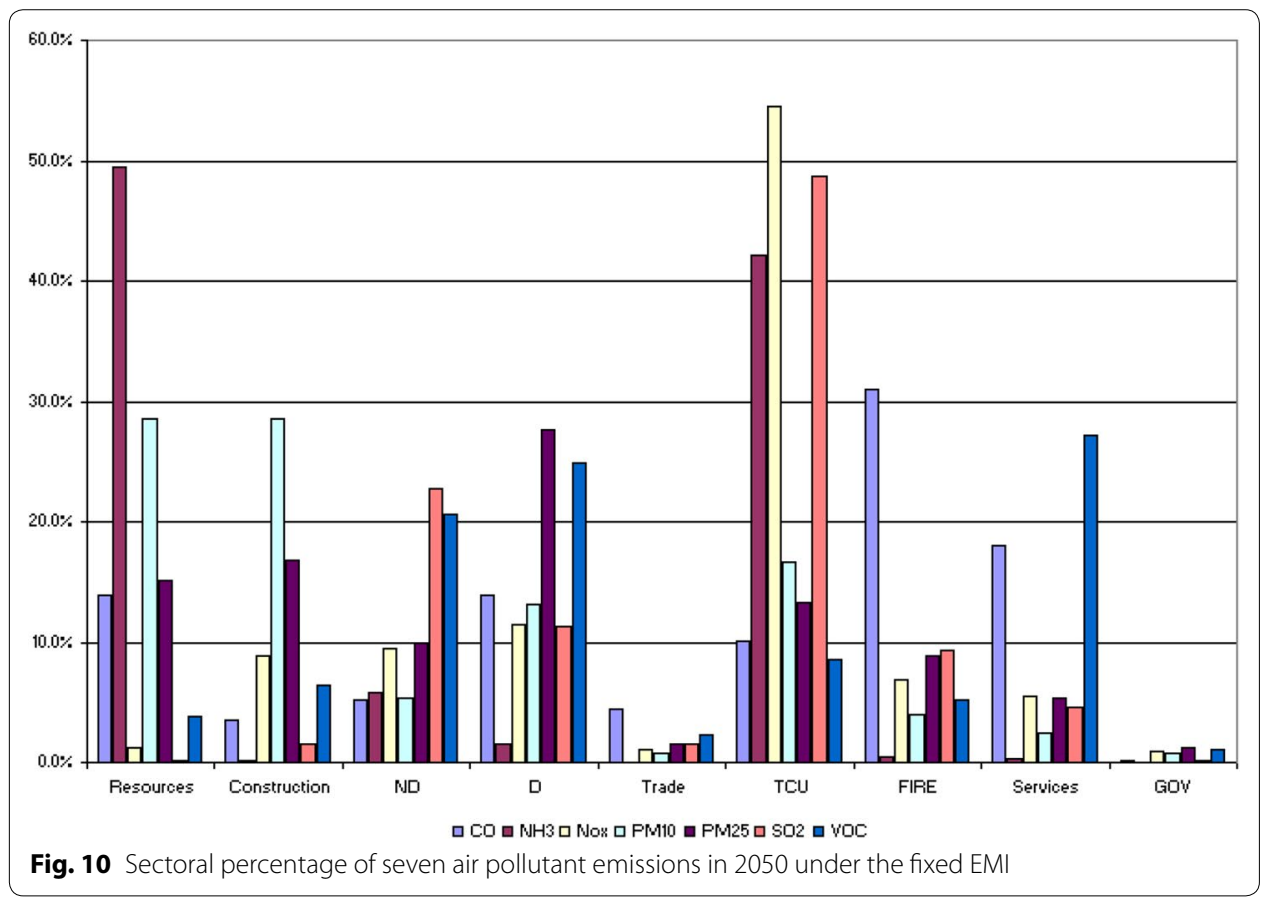




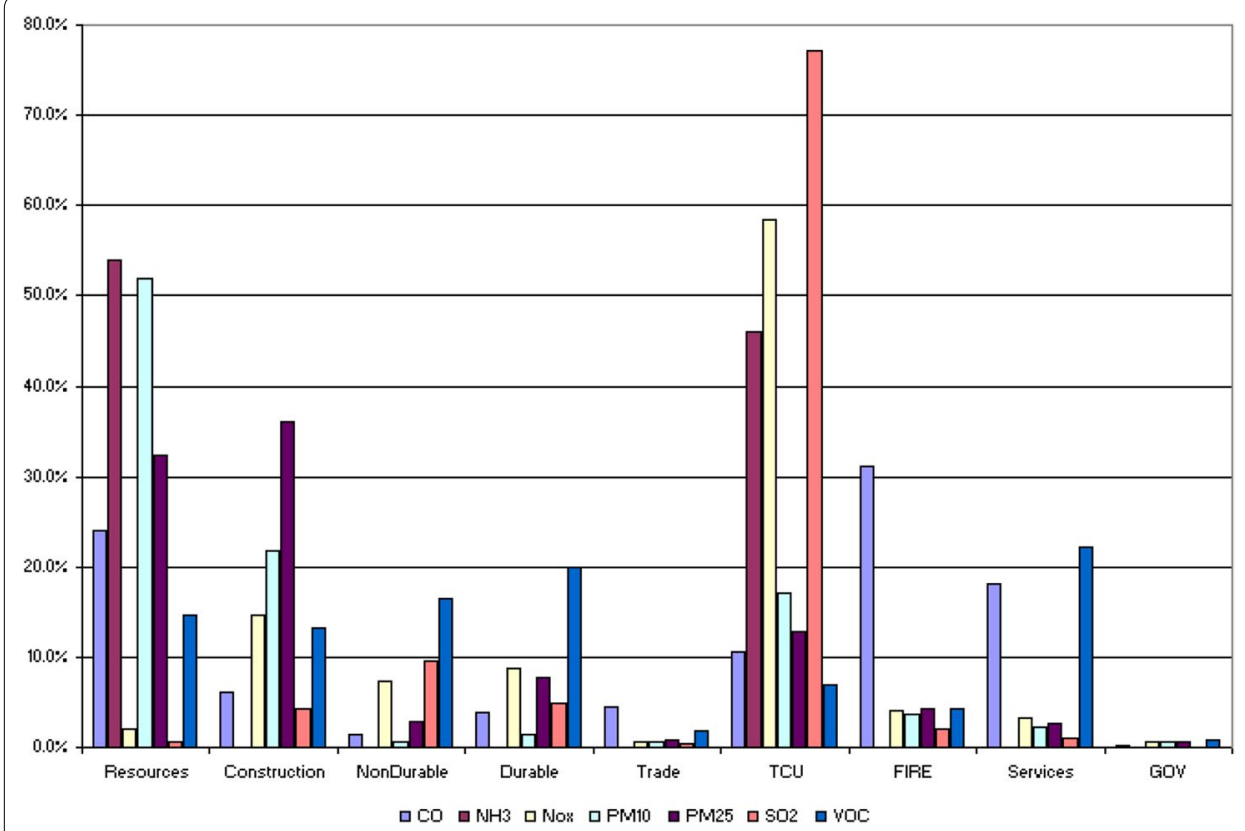

Fig. 11 Percentage distribution of seven air pollutant emissions in 2050 under the time-varying EMI

of $\mathrm{NH}_{3}$ (43\%), $51 \%$ of $\mathrm{NO}_{x}, 30 \%$ of $\mathrm{PM}_{10}$ and $21 \%$ of $\mathrm{PM}_{2.5}$. Durable manufacturing was a significant contributor to $\mathrm{CO}(29 \%), \mathrm{PM}_{2.5}(33 \%)$ and VOC (38\%) emissions while the service sector accounted for $16 \%$ of total CO and $14 \%$ of total VOC emissions. Assuming EMIs do not change from their 1999 values, it is projected that CO emissions produced by durable manufacturing and resources will drop significantly while TCU remains the leading producer of $\mathrm{NH}_{3}, \mathrm{NO}_{x}$ and $\mathrm{SO}_{2}$ emissions (see Fig. 10). Note that, in the fixed coefficients scenario, overall emissions from the FIRE and service sectors increase significantly.

In comparison with the fixed EMI, the relative contribution to emissions from each industry activity changes under the time-varying EMI (see Fig. 11). $\mathrm{PM}_{10}, \mathrm{PM}_{2.5}$ and VOC emissions from resources almost double and, on the other hand, durable and nondurable manufacturing experience significant reductions in emissions; thus, their contribution to total emissions decreases remarkably. Notwithstanding the EMI improvement under the assumption of time-varying EMI, there are two similar results with the fixed EMI assumption. One is that TCU remains the important source of emissions of $\mathrm{NH}_{3}$, $\mathrm{NO}_{x}$ and $\mathrm{SO}_{2}$. The other finding is that FIRE and services assume a growing portion of $\mathrm{CO}$ and $\mathrm{VOC}$ emissions.

\section{Decomposition of the emissions inventory}

\subsection{Emission technology effect and production effect}

Table 4 summarizes the classification of the scenarios that focus on two categories of EMI and two for technological change. The main purpose of the decomposition of emissions inventories is to analyze the relationship between the economic structural changes and emission technology effect of the projected emission inventory. As expected, the simulations indicate that the Chicago economy as a whole will continue growing, but the 
Table 4 Scenario summary

\begin{tabular}{lllll}
\hline \multicolumn{3}{c}{ Scenarios } & & \\
\hline EMI & Fixed & & Time varying & \\
Technological change & None & Varying & None & Varying \\
\hline
\end{tabular}

economic structure will continue to change in this region through 2050. These changes will be apparent in the changing demand for energy; the changes also reflect the different demand and supply relations among the economic sectors over time. On the other hand, technological change in emissions will shift energy usage in industries and consumers. Technological advances will result in a less polluting set of output across industries. At the same time, many policy instruments for environmental protection and regulation will have increased to achieve greater emission reduction since climate change and cleaner air are issues for political moment. Similar analyses have been employed to differentiate technological change from changes in demand in economies over time (see Feldman et al. 1987).

These two economic and environmental features are combined in the simulation results of future emission inventory in the previous section; no attempt was made to differentiate the effects of changes in economic structure and the evolution of emission technology in the Chicago area. To understand which factor plays a more significant role in changing the emission inventory now and in the future, the differences between structural changes in production and changes in emission technology affecting the emission coefficients will be separated. The production effect and emission technological effect are defined by the following relationships:

$$
\begin{aligned}
& \text { Production Effect }=\mathrm{PE}_{j t}=\left(Q_{j t} * E_{k j 99}\right)-\left(Q_{j 99} * E_{k j 99}\right) \\
& \text { Technological Effect }=\mathrm{TCE}_{j t}=\left(Q_{j t} * E_{k j t}\right)-\left(Q_{j t} * E_{k j 99}\right)
\end{aligned}
$$

where $Q_{j t}$ is production in sector $j$ in time $t ; Q_{j 99}$ is production in sector $j$ in 1999; $E_{k i t}$ is the EMI of $k$ pollutant in sector $j$ in time $t$; and $E_{k j 99}$ is the EMI of $k$ pollutant in sector $j$ in 1999.

Then, the total effect (TE) can be derived from the sum of production and technology effect:

$$
\begin{aligned}
\mathrm{TE}_{j t} & =\mathrm{PE}_{j t}+\mathrm{TCE}_{j t} \\
& =\left\{\left(Q_{j t} * E_{k j 99}\right)-\left(Q_{j 99} * E_{k j 99}\right)\right\}+\left\{\left(Q_{j t} * E_{k j t}\right)-\left(Q_{j t} * E_{k j 99}\right)\right\} \\
& =\left(Q_{j t} * E_{k j t}\right)-\left(Q_{j 99} * E_{k j 99}\right)
\end{aligned}
$$

Now it is possible to determine which effect is more influential in contributing to the total emission inventory by using a simple ratio of the technology and production effects. It should be noted that the technology effect does not show a positive value because varying EMI assumes that emission technology will be advanced in the future.

Figure 12 depicts the potential relationships. If the ratio of technology and production effect (hereafter called TCE/PE) is less than zero and greater than -1 , an increasing trend of production makes the emission inventory grow more even though the 


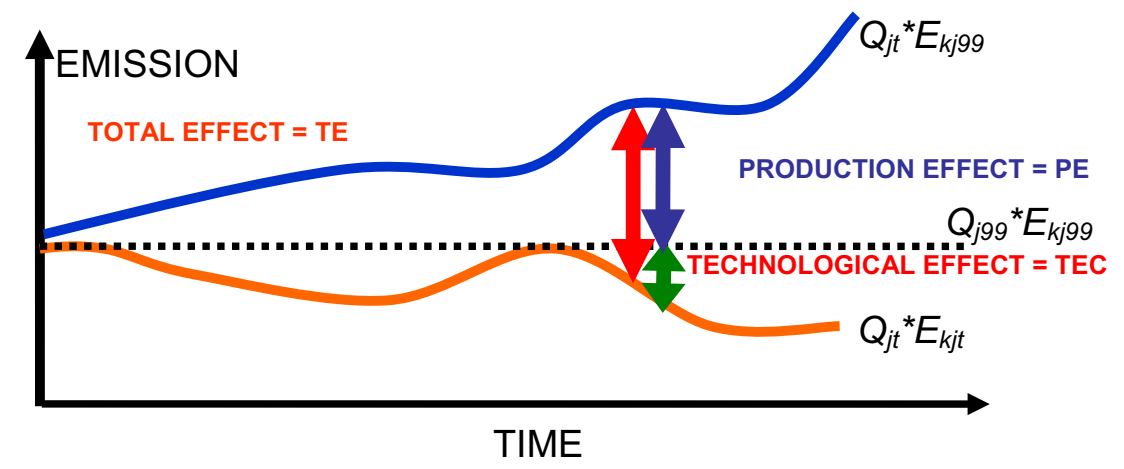

Fig. 12 Graphical decomposition of emission inventory

developed emission technology affects the emission inventory. In the case where TCE/ $\mathrm{PE}$ is between zero and 1, both technology and production effects contribute to decrease the emission inventory, but the decreasing trend of production is more dominant than the enhanced technology effect. On the other hand, if TCE/PE is greater than 1, the decreasing emission inventory is more affected by the technology effect than the falling level of production. In contrast, a higher technology effect causes the emission inventory to decrease even though the level of production is increasing when the ratio of TCE to $\mathrm{PE}$ is less than -1 .

Table 5 shows the classification of the decomposition effects according to the definition of the ratio between technology (TCE) and production effect (PE). Since all of timevarying EMI are assumed to be zero or negative, the focus will be on the two cases that are shaded in Table 5. One is the case where emissions increase because the technology effect cannot prevail over the dominant production effect despite advanced technology $(-1<\mathrm{TCE} / \mathrm{PE}$ ratio $<0)$. The other one is where emissions decrease since the technology effect dominates the growing production effect $(\mathrm{TCE} / \mathrm{PE}$ ratio $<-1)$.

\subsection{Results}

With the detailed sectoral emission decomposition with 2050 projected emission inventory, the comparisons between the dominant production and technology effects are shown in Tables 6 and 7. First of all, CX38 (health care), CX33 (motion picture and sound recording industries), CX46 (federal government enterprise), CX40 (art, entertainment and recreation), CX37 (educational services), CX43 (repair and maintenance), CX42 (food services), CX41 (accommodation services), CX44 (personal and laundry services), CX26 (air transportation) and CX34 (finance and insurance) are categorized as the sectors that affect the increased $\mathrm{CO}$ emissions through dominant production effects.

Table 5 Classification of decomposition effects

\begin{tabular}{llllll}
\hline & & \multicolumn{2}{l}{ Production effect (PE) } & \\
& & Negative & Positive & \\
\hline Technology effect (TCE) & Zero & & Emission $\downarrow$ & Emission $\uparrow$ & PE dominant \\
& Negative & $|\mathrm{TCE}|>|\mathrm{PE}|$ & Emission $\downarrow$ & Emission $\downarrow$ & TCE dominant \\
& & $|\mathrm{TCE}|<|\mathrm{PE}|$ & Emission $\downarrow$ & Emission $\uparrow$ & PE dominant \\
\hline
\end{tabular}


Table 6 Emission inventory decomposition in 2050: sectors for a dominant production effect

\begin{tabular}{|c|c|c|c|c|c|c|}
\hline $\mathrm{CO}$ & $\mathrm{NO}_{x}$ & $\mathrm{NH}_{3}$ & $\mathrm{PM}_{10}$ & $\mathrm{PM}_{2.5}$ & $\mathrm{SO}_{2}$ & VOC \\
\hline CX38 & CX43 & & CX33 & CX44 & CX34 & CX44 \\
\hline CX33 & CX42 & & CX46 & CX26 & & $C \times 26$ \\
\hline CX46 & CX41 & & CX40 & CX34 & & CX34 \\
\hline CX40 & CX11 & & CX37 & & & \\
\hline CX37 & CX44 & & CX43 & & & \\
\hline CX43 & $C \times 26$ & & CX42 & & & \\
\hline CX42 & $C \times 10$ & & CX41 & & & \\
\hline CX41 & CX09 & & CX44 & & & \\
\hline CX44 & CX34 & & CX26 & & & \\
\hline$C \times 26$ & & & CX34 & & & \\
\hline CX34 & & & & & & \\
\hline
\end{tabular}

The sector definitions can be found in Table 2

Table 7 Emission inventory decomposition in 2050: sectors for a dominant technology effect

\begin{tabular}{|c|c|c|c|c|c|c|}
\hline $\mathrm{CO}$ & $\mathrm{NO}_{x}$ & $\mathrm{NH}_{3}$ & $\mathrm{PM}_{10}$ & $\mathrm{PM}_{2.5}$ & $\mathrm{SO}_{2}$ & VOC \\
\hline CX04 & CX35 & CX35 & CX18 & CX35 & CX04 & CX04 \\
\hline CX18 & CX18 & CX18 & CX35 & CX18 & CX35 & CX35 \\
\hline CX35 & CX08 & CX05 & CX05 & CX08 & CX18 & CX18 \\
\hline CX08 & CX32 & CX08 & CX08 & CX32 & CX08 & CX05 \\
\hline CX32 & CX39 & CX39 & CX32 & CX39 & CX39 & CX08 \\
\hline CX39 & $C \times 25$ & CX25 & CX39 & $\mathrm{C} \times 25$ & $C \times 25$ & CX32 \\
\hline CX25 & CX45 & CX45 & CX25 & CX45 & CX45 & CX39 \\
\hline CX15 & CX47 & CX38 & CX15 & CX47 & CX47 & $\mathrm{C} \times 25$ \\
\hline CX11 & CX38 & CX33 & CX11 & CX15 & CX38 & CX45 \\
\hline CX45 & CX33 & CX15 & CX45 & CX38 & CX33 & CX47 \\
\hline CX10 & CX46 & CX40 & CX10 & CX33 & CX46 & CX38 \\
\hline CX09 & CX40 & CX37 & CX09 & CX46 & CX40 & CX33 \\
\hline \multirow[t]{10}{*}{ CX47 } & CX37 & CX11 & CX47 & CX40 & CX37 & CX46 \\
\hline & CX15 & CX43 & CX38 & CX11 & CX15 & CX15 \\
\hline & & CX42 & & CX37 & CX11 & CX40 \\
\hline & & CX41 & & CX43 & CX43 & CX37 \\
\hline & & CX10 & & CX10 & CX42 & CX11 \\
\hline & & CX09 & & CX42 & CX41 & CX43 \\
\hline & & CX44 & & CX09 & $C \times 10$ & CX42 \\
\hline & & $C \times 26$ & & CX41 & CX09 & CX41 \\
\hline & & CX34 & & & CX44 & CX10 \\
\hline & & & & & $C \times 26$ & CX09 \\
\hline
\end{tabular}

Some manufacturing sectors, for example, CX09 (leather and leather products), CX10 (lumber and wood products) and CX11 (paper and allied products) play a significant role in increasing $\mathrm{NO}_{x}$ emissions. There is no sector in which the dominant production effect influences the $\mathrm{NH}_{3}$ emissions' increase in 2050. In general, the results highlighting a dominant production effect could be interpreted as implying that growing production from some services and FIRE industries is responsible for increased future emissions regardless of their advanced technology effect. 
Meanwhile, with advanced technology, a lowered EMI yields decreased CO emissions in CX04 (utilities), CX35 (real estate), CX08 (apparel and textile products), CX09 (leather and leather products), CX10 (lumber and wood products), CX11 (paper and allied products), CX15 (rubber and miscellaneous plastic products), CX18 (fabricated metal products), CX24 (wholesale trade), CX25 (retail trade), CX32 (information), CX39 (social services), CX45 (membership organization) and CX47 (state and local government enterprise) although the production activity of those sectors will have increased by 2050 (first column in Table 6).

For the case of all 7 pollutant emissions, CX08 (apparel and textile), CX15 (rubber and miscellaneous plastic products), CX18 (fabricated metal products), CX25 (retail trade), CX35 (real estate), CX39 (social services) and CX45 (membership organization) are common sectors that demonstrate higher technology effects to reduce these emissions even though there will be increased production effects. Note that for CX04 (utilities), there is a significant technology effect on the decreased emission inventory of $\mathrm{CO}, \mathrm{SO}_{2}$ and VOC. Also, CX35 (real estate) shows the highest technology effect on $\mathrm{NO}_{x}, \mathrm{NH}_{3}$ and $\mathrm{PM}_{2.5}$ emissions than any other sector.

Even if the emissions' technology could be advanced through new technological progress and policy regulations that mandate lower levels of pollution, it is obvious that services and FIRE sectors produce more pollution indirectly because of their increasingly dominant role in the volume of production in the future Chicago economy according to the result of this decomposition analysis. Hence, it is important to highlight which economic activity is more responsive to decreases in the emission inventory associated with their emission technology progress. In particular, Table 7 reveals that CX04 (utilities), CX05 (constructions), CX08 (apparel and textile), CX15 (rubber and miscellaneous plastic products) and CX18 (fabricated metal products) will generate a large technology effect overall on the seven emission pollutants; these findings suggest that more direct approaches in technology development or policy instruments focused on these sectors would contribute most to the reduction in future emission pollutants in Chicago.

\section{Conclusions}

In order to analyze the issues of environmental impacts and economic structural change, an integrated econometric-emission model in continuous time has been developed to project future emissions to reflect Chicago regional changes in both emission generation and the structure of the economy. The CREIM was re-specified and re-estimated as a continuous-time model (CT-CREIM). One of the major advantages is that the CTCREIM provides the opportunity to extend the forecasting period beyond that currently available with the more traditional regional econometric input-output systems that rely on national exogenous forecasts that have a more limited time horizon. In addition, the CT-CREIM can be used to estimate intra-annual impacts (e.g., seasonal pollutant generation).

Using CT-CREIM, an economic-environmental interface was created with two types of emission intensity (EMI), 1999 fixed EMI based on the 1999 National Emission Inventory (NEI) and a time-varying EMI, a measure that takes into account changes in environmental technology and policy. Although on-road mobile sources are a major contributor to total emissions, they were excluded in the estimated emission intensities 
in order to focus on the interaction between technological change and structural change within the Chicago economy. The CT-CREIM integrated econometric-environmental model provides the links to develop and interpret the complex demand-supply relationships with pollutant emissions.

By establishing the relationships between emissions and economic activity for each sector in this integrated model, the results indicate that resource, durable manufacturing and TCU sectors played dominant roles in overall pollution emissions in 1999. According to the forecasted emission under 1999 fixed EMIs, CO emissions produced from durable manufacturing and resources experience a considerable decrease while TCU remains the important contributor to emissions of $\mathrm{NH}_{3}, \mathrm{NO}_{x}$ and $\mathrm{SO}_{2}$. Compared with the fixed EMI scenario, forecasted emissions under the assumption of time-varying EMIs revealed a trend in which increased $\mathrm{PM}_{10}, \mathrm{PM}_{2.5}$ and VOC emissions are generated by resources, but durable and non-durable manufacturing undergo a dramatic reduction in overall emissions. Based on these detailed sectoral emission projections, TCU dominates the production of $\mathrm{NH}_{3}, \mathrm{NO}_{x}$ and $\mathrm{SO}_{2}$ emissions and FIRE and services should be considered as the indirect generation of $\mathrm{CO}$ and $\mathrm{VOC}$ emissions in the future. This finding only indicates that some polluting industry sectors reduce their direct emission and other non-polluting sectors such as FIRE and services increases their share of total emissions. Therefore, further attempts should be made to disaggregate their effects into direct and indirect effects on pollution generation in order to understand how the process of structural changes evolves in transforming emission sources in the Chicago region.

One highlight of this analysis is the decomposition of the technology and production effects on future emission inventories. By differentiating structural changes in production from changes in emission technology affecting the emission coefficients, this analysis found that fast-growing production from services and FIRE industries accounts for a large share of the increased future emissions regardless of technological advances in pollution reduction. This finding suggests that services and FIRE industries are important indirect sources of emission pollution. In contrast, higher technology effects to reduce the emissions are found in CX04 (utilities), CX08 (apparel and textile), CX15 (rubber and miscellaneous plastic products), CX18 (fabricated metal products) and CX35 (real estate) even if their production effects increase.

The most important contribution of this study is the development of an integrated system that characterizes both the changing structure of the economy and changes in emission intensity. However, the ability of the model to support long-range emissions forecasting depends heavily on the stability of the estimated model and assumptions about the evolution of EMIs. This being the case, future research should investigate the sensitivity of the model's stability to changes in specification or parameterization and alternative ways to represent emissions generation in the model.

\section{Authors' contributions}

GH and KD were responsible for the organization of the study, the write-up and editing. CW provided guidance in the use of the continuous time methodology that was implemented by SH. All authors read and approved the final manuscript.

\section{Author details}

'Department of City and Regional Planning, Cornell University, 106 West Sibley Hall, Ithaca, NY 14853, USA. ${ }^{2}$ Sapienza University of Rome, Rome, Italy. ${ }^{3}$ Regional Economics Applications Laboratory, University of Illinois, 607 S. Mathews, 
\#318, Urbana, IL 61801-3671, USA. ${ }^{4}$ Korea Research Institute for Human Settlements, 1591-6 Kwanyang-Dong, Dongan-Gu, Anyang-Si, Kyounggi-Do 431-712, South Korea.

\section{Acknowledgements}

The authors would like to thank two anonymous referees and the Editor for their careful reading of earlier drafts and the valuable suggestions they provided. Marcelo Lufin provided valuable assistance in the preparation of the econometric model. Funding from the US Environmental Protection Agency was instrumental in developing the continuous-time version of the model. All opinions and interpretations in the paper are those of the authors.

\section{Competing interests}

The authors declare that they have no competing interests.

\section{Consent for publication}

Not applicable.

Ethics approval and consent to participate

Not applicable.

\section{Publisher's Note}

Springer Nature remains neutral with regard to jurisdictional claims in published maps and institutional affiliations.

Received: 31 October 2016 Accepted: 23 August 2017

Published online: 06 September 2017

\section{References}

Allen RGD (1965) Mathematical economics, 2nd edn. Macmillan \& Company, London

Arbia G, Paelinck JH (2003) Spatial econometric modeling of regional convergence in continuous time. Int Reg Sci Rev 26:342-362

Babiker MH, Reilly JM, Mayer M, Eckasus RS, Wing LS, Hyman RC (2001) The MIT emissions prediction and policy analysis (EPPA) model: revisions, sensitivities, and comparisons of results. In: MIT joint program report 71

Bergstrom AR (ed) (1976) Statistical inference in continuous economic models. North-Holland Publishing Company, Amsterdam

Conrad K, Schroder M (1993) Choosing environmental policy instruments using general equilibrium models. J Policy Model 15:521-543

Conway RS (1990) The Washington Projection and Simulation Model: a regional interindustry econometric model. Int Reg Sci Rev 13:141-156

Conway RS (1991) An empirical comparison of regional multipliers. In: Dewhurst JL, Hewings GJD, Jensen RC (eds) Regional input-output modeling: new developments and interpretations. Aldershot, Avebury, pp 178-195

Donaghy KP (2001) Solution and econometric estimation of spatial dynamic models in continuous space and continuous time. J Geogr Syst 3:257-270

Donaghy KP, Plotnikova M (2004) Econometric estimation of a spatial dynamic model in continuous space and continuous time: an empirical demonstration. In: Getis A, Mur J, Zoller HG (eds) Spatial econometrics and spatial statistics. Palgrave, New York, pp 104-131

Donaghy KP, Balta-Ozkan N, Hewings GJD (2007) Temporal disaggregation in a regional econometric input-output model. Econ Syst Res 19:125-145

Feldman SJ, McClain D, Palmer K (1987) Sources of structural change in the United States, 1963-1978: an input-output perspective. Rev Econ Stat 69:503-510

Forsund FR (1985) Input-output models. National economic models and the environment. In: Kneese AV, Sweeney JL (eds) Handbook of natural resource and energy economics, vol 1. North Holland, Amsterdam

Fritz O, Sonis M, Hewings GJD (2002) Direct and indirect industrial pollution generation: a field of influence approach. In: Hewings GJD, Sonis M, Boyce D (eds) Trade, networks and hierarchies. Springer, Heidelberg

Gandolfo G (1981) Qualitative analysis and econometric estimation of continuous time dynamic models. North-Holland Publishing Company, Amsterdam

Harvey AC (1989) Forecasting structural time series models and the Kalman filter. Cambridge University Press, Cambridge Hazilla M, Kopp RJ (1990) Social cost of environmental quality: a general equilibrium analysis. J Polit Econ 98(4):853-873 Hertel TW, McDougall R (2003) GTAP Model Version 6.2, Center for Global Trade Analysis. Purdue University Hewings GJD, Mahidhara R (1996) Economic impacts: lost income, ripple effects and recovery. In: Changnon S (ed) The Great Flood of 1993. Westview Press, Boulder, CO

Hewings GJD, Sonis M, Guo J, Israilevich PR, Schindler GR (1998) The hollowing-out process in the Chicago economy, 1975-2015. Geogr Anal 30:217-233

Igos E, Rugani B, Rege S, Benetto E, Drouet L, Zachary D, Haas T (2015) Integrated environmental assessment of future energy scenarios based on economic equilibrium models. FEEM Working Paper No. 9.2015. Available at SSRN: https://ssrn.com/abstract $=2565685$ or doi:10.2139/ssrn.2565685

IPCC (intergovernmental panel on climate change) (2007) Climate change 2007: climate change impacts, adaptation and vulnerability — summary for policy makers, the contribution of working Group II to the fourth assessment of the Intergovernmental Panel on Climate Change. http://www.ipcc.ch/SPMavr07.pdf

Isard W (1972) Ecologic-economic analysis for regional development. Johns Hopkins Press, Baltimore, MD 
Israilevich PR (2002) Frame-shifting in regional general equilibrium models. In: Hewings GJD, Sonis M, Boyce D (eds) Trade, networks and hierarchies: modelling regional and interregional economies. Springer, Heidelberg Israilevich PR, Hewings GJD, Schindler GR, Mahidharha R (1996) The choice of input-output table embedded in regional econometric input-output models. Pap Reg Sci 75:103-119

Israilevich PR, Hewings GJD, Sonis M, Schindler GR (1997) Forecasting structural change with a regional econometric input-output model. J Reg Sci 37:565-590

Ivanova D, Stadler K, Steen-Olsen K, Wood R, Vita G, Tukker A, Hertwich EG (2016) Environmental impact assessment of household consumption. J Ind Ecol 20:526-536. doi:10.1111/jiec.12371

James DE (1985) Environmental economics, industrial processes and regional residuals models. In: Kneese AV, Sweeney $J \mathrm{~L}$ (eds) Handbook of natural resource and energy economics, vol 1. North Holland, Amsterdam

Jorgenson DW, Wilcoxon PJ (1990a) Environmental regulation and US economic growth. J Econ 21(2):314-340

Jorgenson DW, Wilcoxon PJ (1990b) Intertemporal general equilibrium modelling of US environmental regulation. J Policy Model 12(4):714-744

Ketkar KW (1984) Environmental protection policies and the structure of the US economy. Appl Econ 16:237-256

Lenzen M, Pade L, Munksgaard J (2004) $\mathrm{CO}_{2}$ multipliers in multi-region input-output models. Econ Syst Res 16:391-412

Leontief WW (1970) Environmental repercussions and the economic structure. Rev Econ Stat 52:262-271

Leontief WW, Ford D (1972) Air pollution and the economic structure: empirical results of input-output computations. In: Brody A, Carter AP (eds) Input-output technique. North Holland, Amsterdam

Lesuis P, Muller F, Nijkamp P (1980) An interregional policy model for energy-economic-environmental interactions. Region Sci Urban Econ 10(3):343-370

Meyer B, Lutz C, Wolter I (2004) Economic growth of the EU and Asia: a first forecast with the global econometric model GINFORS. Policy and Governance Paper Series, No. 26, Tokyo, Keio University

Munksgaard J, Pedersen KA, Wier M (2000) Impact of household consumption on $\mathrm{CO}_{2}$ emissions. Energy Econ 22:423-440

Munroe DK, Hewings GJD, Guo D (2007) The role of intraindustry trade in interregional trade in the Midwest of the US. In: Cooper RJ, Donaghy KP, Hewings GJD (eds) Globalization and regional economic modeling. Springer, Heidelberg

NEl99 (National Emission Inventory). http://www.epa.gov/ttn/chief/net/1999inventory.html

Oosterhaven J, van der Linden JA (1997) European technology, trade and income changes for 1975-85: an intercountry input-output decomposition. Econ Syst Res 9:393-411

Oud JHL, Folmer H (2008) A structural equation approach to models with spatial dependence. Geogr Anal 40(2):152-166

Pedersen OG (1996) Input-output analysis and emissions of $\mathrm{CO}_{2}, \mathrm{SO}_{2}$ and $\mathrm{NO}_{x}$-linking physical and monetary data. In: Madsen B, Jensen-Butler C, Mortensen JB, Christensen AMB (eds) Modelling the economy and the environment. Springer, Berlin

Phillips PCB (1991) Error correction and long-run equilibrium in continuous time. Econometrica 59:967-980

Piras G, Donaghy KP, Arbia GJ (2007) Nonlinear regional economic dynamics: continuous time specification, estimation, and stability analysis. J Geogr Syst 9:311-344

Rhee JJ, Miranowski JA (1984) Determination of income, production, and employment under pollution control: an inputoutput approach. Rev Econ Stat 57:146-150

Romero I, Dietzenbacher E, Hewings GJD (2009) Fragmentation and complexity: analyzing structural change in the Chicago regional economy. Rev Econ Mund 23:263-282

Round JI (1985) Decomposing multipliers for economic systems involving regional and world trade. Econ J 95:383-399

Shampine LF, Gordon MK (1975) Computer solution of ordinary differential equations. Freeman, New York

Sonis M, Hewings GJD (1992) Coefficient change in input-output models: theory and applications. Econ Syst Res 4:143-157

Sonis M, Hewings GJD (1996) Sources of structural change in input-output systems: a field of influence approach. Econ Syst Res 8(1):15-32

Springer K (2002) Climate policy in a globalizing world: a CGE model with capital mobility and trade. Springer, Berlin

Takayama A (1985) Mathematical economics. Cambridge University Press, Cambridge

Tao Z, Williams A, Donaghy K, Hewings GJD (2007) A socio-economic method for estimating future air pollutant emissions-Chicago case study. Atmos Environ 41:5398-5409

Tao Z, Hewings GJD, Donaghy KP (2010) An economic analysis of trends of mid-western US pollutant emissions from 1970 to 2000. Ecol Econ 69:1666-1674

Uno K (2002) Energy projections: comparison of methodologies. In: Uno K (ed) Economy-energy-environment simulation: beyond the Kyoto protocol. Springer, Berlin

Wiedmann T, Wood R, Minx J, Lenzen M, Guan D, Harris R (2010) A carbon footprint time series of the UK—results from a multi-region input-output model. Econ Syst Res 22:19-42. doi:10.1080/09535311003612591

Wood R, Dey CJ (2009) Australia's carbon footprint. Econ Syst Res 21:243-266. doi:10.1080/09535310903541397

Wymer CR (1972) Econometric estimation of stochastic differential equation systems. Econometrica 40:565-577

Wymer CR (1993) Estimation of nonlinear continuous-time models from discrete data. In: Phillips P, Hall V (eds) Models, methods, and application of econometrics. Basil Blackwell, Oxford

Wymer CR (1997) Structural non-linear continuous-time models in econometrics. Macroecon Dyn 1:518-548

Wymer CR (2004) Systems estimation and analysis programs (WYSEA), Auckland, New Zealand 